\title{
Microcircuits in nucleus accumbens' shell and core involved in cognition and reward
}

\author{
GLORIA E. MEREDITH \\ Royal College of Surgeons in Ireland, Dublin, Ireland \\ and \\ SUSAN TOTTERDELL \\ University of Oxford, Oxford, England
}

\begin{abstract}
Nucleus accumbens subserves numerous adaptive and goal-directed behaviors. The anatomical substrates for such are the medium spiny projection neurons, at least four different subtypes of local circuit neurons, and inputs from limbic cortical centers and brainstem monoamines. In this review, we show how microcircuits in two parts of the nucleus-the core and caudomedial shell or septal polediffer subtly in their connections yet permit quite different behaviors. We further show how small differences in synaptic wiring, especially in relation to the local circuit neurons, can facilitate or suppress behavioral activity. Finally, we consider some important organizational principles that underlie cognitive, emotional, and rewarding behaviors.
\end{abstract}

Nucleus accumbens, which makes up a large part of the ventral striatum, was originally thought to regulate locomotor activity and exert some control over motivational and emotional behavior, including playing a role in the processes underlying schizophrenia (Matthysse, 1978; Stevens, 1973). Early work showed that the pharmacological stimulation of dopamine in this nucleus brought about increases in locomotion (Pijnenburg \& Van Rossum, 1973), self-stimulation (Broekkamp, Pijnenburg, Cools, \& Van Rossum, 1975), and, with amphetamine administration, stereotypical behavior (Pijnenburg, Honig, \& Van Rossum, 1975). When Mogenson, Jones, and Yim (1980) coined the now classical term limbic-motor interface, nucleus accumbens came to be viewed as the key site for gating motivational and other emotional signals in order to convert them into adaptive motor responses; dopamine served as the neural facilitator for that translation. Early neuroanatomical studies established links between limbic cortical centers and nucleus accumbens (Heimer \& Wilson, 1975) and between the dopaminergic neurons in the ventral midbrain and this nucleus (Nauta, Smith, Faull, \& Domesick, 1978). Access to motor circuits was considered to occur via the globus pallidus, a structure from

This research was supported by a Health Research Board Grant to G.E.M., Wellcome Trust Project Grant 042767/94 to S.T., and an international collaboration grant from Forbairt (Ireland) to G.E.M. and S.T. The authors thank B. L. Roberts for comments on the manuscript, P. Emson for the gift of NOS antibodies, and A. McFarlane, H. Chang, L. Johnson, and Z. Hussain for providing some immunolabeled tissue. The authors also thank the Media Services Department at the Royal College of Surgeons in Ireland for photographic assistance. Correspondence should be addressed to G. E. Meredith, who is now at the Department of Basic Medical Science, University of Missouri--Kansas City, School of Medicine, 2411 Holmes St., Room M3-C03, Kansas City, MO 64108-2792. which locomotion could be elicited with injections of picrotoxin, a GABAergic antagonist (see Mogenson \& Yim, 1981, Figure 9). More recent anatomical investigations, however, have shown that the outflow from accumbens, instead of exiting via a single efferent route, follows multiple, parallel pathways to different centers in the forebrain and brainstem (Groenewegen \& Russchen, 1984; Heimer, Zahm, Churchill, Kalivas, \& Wohltmann, 1991; Zahm \& Brog, 1992; Zahm \& Heimer, 1988). Moreover, behavioral, physiological, and pharmacological studies suggest that complex synaptic and nonsynaptic interactions within the nucleus itself could account for important nuances in adaptive behaviors (Austin \& Kalivas, 1988; Bakshi \& Kelley, 1994; Deutch \& Cameron, 1992; Kalivas \& Duffy, 1995; Ma, Brudzynski, \& Leung, 1996; Wan \& Swerdlow, 1996). Thus, as more connectional data for nucleus accumbens have become available, its role in gating limbic inputs (Mogenson et al., 1980) has taken on new, more highly complex meanings.

Nucleus accumbens, which is very rich in neurotransmitters and neuropeptides, contains both projection and local circuit neurons that are connected not only with each other but also with diverse inputs from cortical, subcortical, and brainstem centers. Although many details are still lacking, we are now beginning to understand how these cells and their connections form microcircuits, wired to subserve diverse functions. In this review, we will examine these units in some detail in order to provide a basic framework from which to hang broad behavioral concepts. We will look at the structural properties of the circuits with particular reference to their relationship with incoming monoamine pathways and local circuit neurons, and, finally, we will provide some insight into how drugs, lesions, and behavior can alter synapses and, thus, the circuits in which they participate. 


\section{NEUROCHEMICAL ARCHITECTURE}

Nucleus accumbens, like the caudate and putamen in the dorsal striatum, is compartmentally organized. The organizational pattern, however, is really very different. In contrast to the bicompartmental, striosome or patch and matrix, pattern in the dorsal striatum, accumbens has two large, neurochemically and cytoarchitecturally complex compartments, termed shell and core (Figures 1 and 2; Jongen-Rêlo, Groenewegen, \& Voorn, 1993; Meredith, Blank, \& Groenewegen, 1989; Voorn, Gerfen, \& Groene- wegen, 1989; Záborszky et al., 1985; Zahm \& Brog, 1992). A third division, referred to as the rostral pole, occupies roughly the foremost one fourth of the nucleus in rats (Zahm \& Brog, 1992; Zahm \& Heimer, 1993) but has not, as yet, been distinguished in human or other primates (Meredith, Pattiselanno, Groenewegen, \& Haber, 1996). While the rostral pole in the rat appears to stand alone on the basis of its efferent connections (Zahm \& Heimer, 1993), it does contain rostral extensions of the neurochemical labeling that define shell and core territories (Jongen-Rêlo, Voorn, \& Groenewegen, 1994; Meredith,

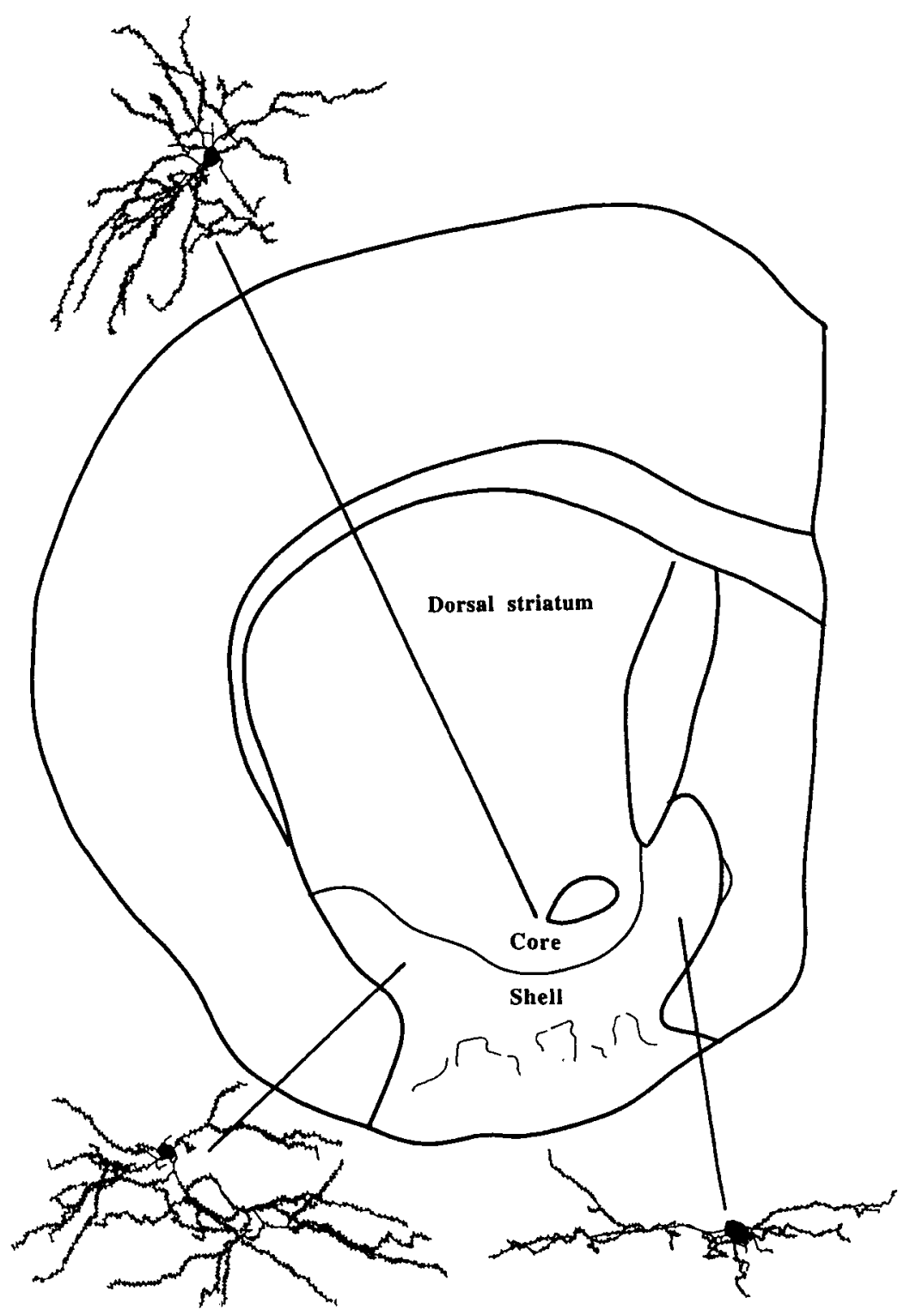

Figure 1. Drawing depicting the major compartmental divisions at a caudal level of nucleus accumbens, shell, and core. Computerized reconstructions of principal neurons located in the medial shell (to the right), lateral shell (to the left), and core. Note the larger number of primary dendrites and spherical dendritic field of the core and lateral shell neurons, relative to those of the neuron at the septal pole. 

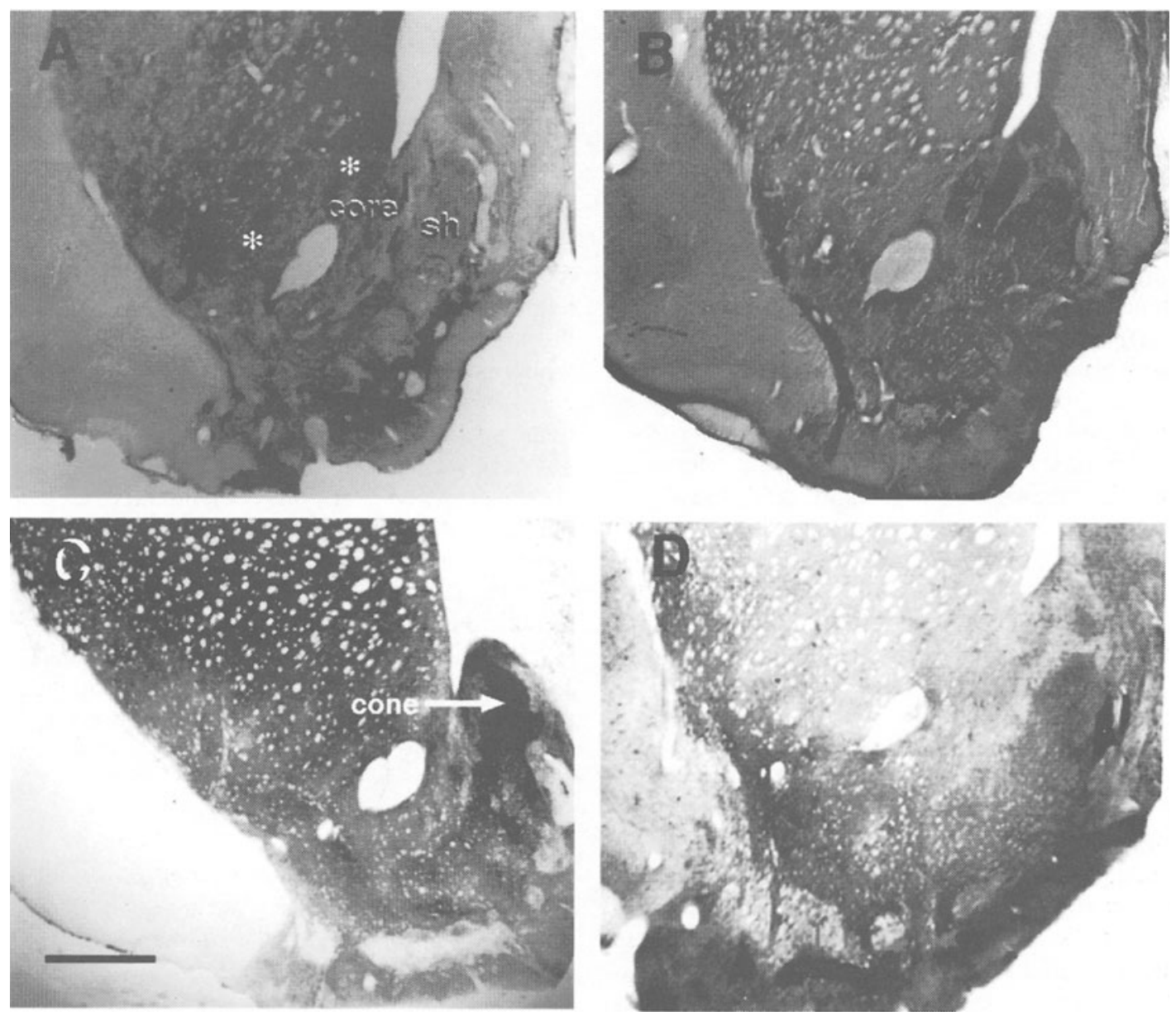

Figure 2. Light micrographs illustrating the regional variation in the distribution of the opioid peptides, enkephalin (A) and dynorphin (B), and the rate-limiting enzymes for the production of dopamine, TH (C), and nitric oxide, NOS (D). Photomicrographs are all taken through a caudal level of nucleus accumbens. Core and shell (sh) are labeled in $A$, and cone area of the septal pole is labeled in C. Stars in A mark enkephalin-rich zones. Medial is to the right of each micrograph, and the scale bar in $C$, which is equal to $1 \mathrm{~mm}$, is valid for $A-D$.

Pennartz, \& Groenewegen, 1993), thus making it contiguous, at least from a chemical standpoint, with the two compartments.

Sharp regional variations in neurochemical content (Fonnum \& Walaas, 1981; Voorn et al., 1989; Zahm \& Heimer, 1988), receptor distribution and uptake sites (Bardo \& Hammer, 1991; Herkenham, Moon Edley, \& Stuart, 1984; Jongen-Rêlo et al., 1993), and afferent and efferent connections (Brog, Salyapongse, Deutch, \& Zahm, 1993; Heimer et al., 1991) occur within the two territories. For example, in the core, rostrolateral and caudal enkephalin-rich areas (Figure 2A) coincide with opioid receptor patches (Jongen-Rêlo et al., 1993); in the shell, patterns of opioid receptors, cell clusters, dopamine, choline acetyltransferase (ChAT), calcium binding protein D28k (CaBP), and the two opioid peptides, enkephalin (Figure 2A) and dynorphin (Figure 2B), either avoid or overlap one another in marked heterogeneous patterns (Herkenham et al., 1984; Jongen-Rêlo et al., 1993; Meredith et al., 1989; Meredith, Pennartz, \& Groenewegen, 1993; Voorn et al., 1989). Dense substance $P$ and low neurotensin immunoreactivity overlie basal cell clusters ventrally in the caudal shell (Zahm \& Heimer, 1988).

To understand the functional bases for motivational behavior, characterizing nucleus accumbens only in terms of shell, core, and rostral pole may not be enough. Beginning with the observations of Chronister, Sikes, Trow, and DeFrance (1981), attention has been increasingly focused on mediolateral differences in neurochemical content and connections of this nucleus (Alheid \& Heimer, 1988; Fonnum \& Walaas, 1981; Groenewegen \& Russchen, 1984; Groenewegen, Vermeulen-Van der Zee, te Kortschot, \& Witter, 1987; Meredith et al., 1989; Phelps \& Vaughn, 1986; Voorn et al., 1989; Wright \& Groenwegen, 1995). Indeed, there is now good evidence to show that caudomedial nucleus accumbens, the septal pole 
(Figure 1; Voorn, Jorritsma-Byham, Van Dijk, \& Buijs, 1986), while an intrinsic part of the shell, is also a transition zone between the extended amygdala and the rest of the striatum (Alheid \& Heimer, 1988). The transitional nature of the septal pole becomes obvious when we consider its complex anatomical, hodological, and chemical features. This is where clusters of tightly packed small cells, which are dense in opioid receptors, reside (Herkenham et al., 1984); prefrontal, amygdalar, hippocampal, and midline thalamic inputs intermingle or avoid one another (Wright \& Groenewegen, 1995; Zahm \& Brog, 1992); dopaminergic fibers, as illustrated in Figure 2C by the distribution of tyrosine hydroxylase (TH) immunoreactivity, are distributed densely to the cone, where they provide a proximal input to the principal cells (Meredith, Pennartz, \& Groenewegen, 1993; Voorn et al., 1986); and neuroactive substances, such as cholecystokinin, neurotensin, nitric oxide, as demonstrated via nitric oxide synthase antiserum (Figure 2D), and dynorphin (Figure 2A) are concentrated, and enkephalin (Figure $2 \mathrm{~A}$ ) is weak to moderately dense (Jongen-Rêlo et al., 1993; Van Bockstaele, Sesack, \& Pickel, 1994; Záborszky et al., 1985; Zahm \& Heimer, 1988).

\section{MORPHOLOGICAL SUBSTRATE}

\section{Principal Neurons}

The principal neurons (which are often called densely spiny neurons) account for roughly $90 \%$ of the total number of cells in nucleus accumbens. They use $\gamma$-aminobutyric acid (GABA) as a primary neurotransmitter and contain a variety of neuropeptides, including substance $P$, neurotensin, and the opioids enkephalin and dynorphin (Meredith, Pennartz, \& Groenewegen, 1993; Pickel, Joh, \& Chan, 1988; Zahm \& Brog, 1992). They are small to medium in size, measuring approximately $100 \mu \mathrm{m}^{2}$ in cross-sectional area or $11.5 \mu \mathrm{m}$ in diameter (a range of 9-20 $\mu \mathrm{m}$ ) and have three to six primary dendrites that are initially spine-free and farther distally become laden with spines (Chang \& Kitai, 1985; Meredith, Agolia, Arts, Groenewegen, \& Zahm, 1992; O’Donnell \& Grace, 1993b). The axon typically emerges from the cell soma and arborizes in the region of the dendritic tree, where synapses repeatedly occur with neighboring cells, before leaving the nucleus (Chang \& Kitai, 1985; O'Donnell \& Grace, 1993b). The perikarya are round, with a single large nucleus, one or two nucleoli, and a smooth nuclear envelope and are surrounded by a thin rim of cytoplasm containing all the usual organelles. The perikaryal membrane is often juxtaposed by glia and generally receives few axosomatic synaptic contacts (Meredith, Wouterlood, \& Pattiselanno, 1990). Synapses are found on proximal and distal dendrites, and each spine usually receives an asymmetrical input to the head and a symmetrical terminal at the neck (Wilson, Groves, Kitai, \& Linder, 1983).

In general, principal neurons in the caudomedial shell have fewer primary dendrites and spines than their coun- terparts in the core or in lateral parts of the shell (Figure 1; Meredith et al., 1992; O'Donnell \& Grace, 1993b). In addition, dendritic trees of medial shell neurons are elongate, whereas those elsewhere are more spherical (Figure 1; O'Donnell \& Grace, 1993b). While the structure of core cells is generally uniform, that of shell neurons varies significantly. Spine density, total dendritic length, and number of dendritic branches increase along a medial-to-lateral gradient, such that, laterally, principal neurons more closely resemble those in the core than at the septal pole (Figure 1; Meredith et al., 1992). In line with these site-specific morphologies are regional differences in membrane properties. The mean resting membrane potentials (a range of -90 to $-50 \mathrm{mV}$ ) are less negative, and the mean input resistances are greater for medial shell than for core neurons (O'Donnell \& Grace, 1993b; Pennartz, Ameerun, Groenewegen, \& Lopes da Silva, 1993; Pennartz, Dolleman-Van der Weel, \& Lopes da Silva, 1992). In addition, neurons in the medial shell (septal pole) have significantly lower membrane time constants than do those in the core (O'Donnell \& Grace, 1993b). These differences, when taken together, reflect the overall lower surface area in cells at the septal pole, relative to those more rostral or lateral in the shell or in the core.

\section{Local Circuit Neurons}

Local circuit neurons were recognized in early studies of the nucleus accumbens (Chronister et al., 1981), and they may comprise up to $10 \%$ of total accumbal neurons (Thomas, Vaid, \& Totterdell, 1995). They vary greatly in size (Figure 3); their perikarya may be round or elongated, usually with an eccentric nucleus and an indented nuclear envelope. Their dendrites vary in extent and generally lack spines but are sometimes varicose. They are complex neurochemically: They can be grouped into at least four different, nonoverlapping populations (Hussain, Johnson, \& Totterdell, 1996), which, with the exception of the giant cholinergic neurons, are GABAergic (Kawaguchi, Wilson, Augood, \& Emson, 1995).

The first two groups of GABAergic neurons contain one of two calcium binding proteins, parvalbumin (PV) or calretinin (Figures $3 \mathrm{~A}$ and $3 \mathrm{C}$ ). The PV-positive cells are medium in size (10-22 $\mu \mathrm{m}$ in diameter) and range from oval to multipolar, usually with two to three primary dendrites (Figure 3A). Some dendrites extend over a considerable distance without further branching, but others branch more often close to the soma. The dendrites appear smooth, being neither varicose nor spiny, and they taper quickly from the cell body. The calretinin-positive neurons (Figure $3 \mathrm{C}$ ) are usually unipolar or bipolar but rarely multipolar. They all have small perikarya $(8-14 \mu \mathrm{m}$ in diameter) and long dendrites that branch occasionally and become varicose distally.

The density of PV neurons in nucleus accumbens is lower than in the dorsal striatum, where they decrease in density along a lateral to medial gradient (Bennett \& Bolam, 1994). In accumbens, their distribution is not ap- 

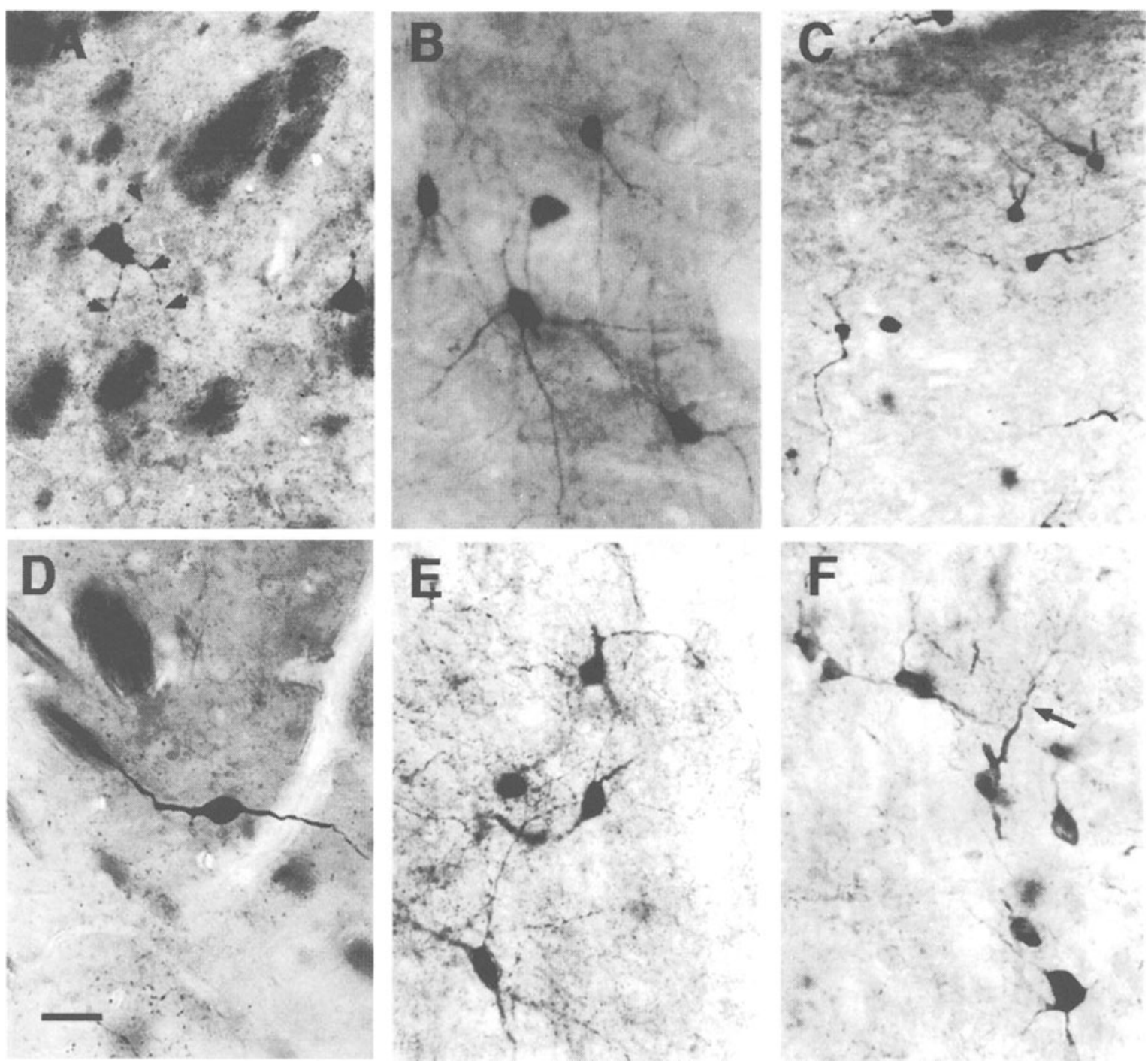

Figure 3. Light micrographs of subtypes of local circuit neurons found in nucleus accumbens. The range in size of the perikarya can clearly be seen, since all cells are pictured at the same magnification. (A) Multipolar (arrowheads) and bipolar PV-immunoreactive neurons (silver-intensified gold deposit); (B) ChAT-immunolabeled (Vector SG) neurons; (C) calretininpositive (Vector SG) neurons (note the long, thin dendritic processes); (D) a bipolar somatostatin-immunoreactive neuron (silverintensified gold deposit); (E) NADPH-diaphorase-stained neurons (note the plexuses of fibers and long, extensive dendrites of the cells); (F) NOS-immunolabeled neurons (DAB) (note the tortuous dendritic processes [arrow] on some cells). Scale bar in $D$, which is equal to $20 \mu \mathrm{m}$, is valid for $A-F$.

parently linked to the core/shell divisions, although Sadikot, Rudkin, and Smith (1996) report a preferential distribution in the shell. Parvalbumin-positive neurons are more numerous in the rostral pole than they are farther caudally; they are rare at the septal pole but can be found in the ventral shell and core at caudal levels. In contrast, there are more calretinin-positive neurons in nucleus accumbens than in the dorsal striatum (Sadikot et al., 1996, but see Hussain et al., 1996). Moreover, their density medially exceeds that laterally, but there are no obvious core/shell differences. These neurons are also found in the rostral pole, although we have no evidence for an increase in density rostrally as reported in the dorsal striatum
(Bennett \& Bolam, 1993). Calretinin-immunoreactive fibers characteristically form a dense but heterogeneous innervation of the medial shell (Hiroi, 1995), whereas they are less dense in the lateral shell and core.

The third major class of medium-sized interneurons is, at least in the dorsal striatum, not only GABAergic but also immunopositive for the neuropeptides, somatostatin (Figure 3D), and neuropeptide Y (NPY) and contains the neuronal form of nitric oxide synthase (NOS; Figure 3F) and NADPH-diaphorase (Figure 3E; Kawaguchi \& Kubota, 1995). These neurons have somata that are bipolar, fusiform, or multipolar (compare Figures 3D, $3 \mathrm{E}$, and $3 \mathrm{~F}$ ) and long dendrites, which branch infrequently 
and become varicose and highly tortuous distally (Hussain et al., 1996). The NOS-positive neurons (Figure 3F) are small to medium in size $(8-18 \mu \mathrm{m}$ in cross-sectional diameter) in both shell and core. There is no overall difference in the distribution of these cells, and fiber staining in the medial part of the shell is not homogeneousthat is, there is a region of low staining intensity at the most dorsal part of the septal pole, which is complemented by the "cone" region immediately below that shows particularly intense fiber staining (Figure 2D).

The local circuit neurons in the final group contain acetylcholine and can be visualized using antibodies to the enzyme, choline acetyltransferase (ChAT). Perikarya (Figure 3B) may be round, fusiform, or triangular with one to three primary dendrites, which are long and smooth and branch infrequently. These neurons are typically large (Figure 3B), measuring 15-35 $\mu \mathrm{m}$ across the long diameter (Phelps \& Vaughn, 1986), but are significantly smaller than their dorsal striatal counterparts, which have long diameters of 20-50 $\mu \mathrm{m}$ (Kawaguchi et al., 1995; Phelps \& Vaughn, 1986). At the septal pole, the cholinergic cells (a mean diameter of $14 \mu \mathrm{m}$ ) are significantly smaller than those (a mean diameter of $20 \mu \mathrm{m}$ ) in the core (Meredith, Pennartz, \& Groenewegen, 1993). Cholinergic neurons are the least dense rostrally, with their density increasing rapidly through the rostral quarter of the nucleus and falling off sharply farther caudally (Meredith et al., 1989). Cell density is greatest in the shell, especially at the septal pole, where it is nearly three times higher than that in the core and five times greater than that at the rostral pole. The increased density also coincides with dense plexuses of immunoreactive fibers. In the core, cells are denser in the regions surrounding enkephalin-positive "patches" than within them (Meredith et al., 1989).

Finally, there are reports of intrinisic neurons containing cholecystokinin (CCK) or vasoactive intestinal peptide (VIP) in the striatum (Tagaki et al., 1984; Theriault \& Landis, 1987), but these have yet to be investigated fully.

\section{Receptors}

Dopamine plays a powerful role in the regulation of motor activity and emotional and goal-directed behaviors, exerting its effects by interacting with two families of G-protein-coupled receptors: the D1-like and D2-like (Kebabian \& Calne, 1979). Other receptors, such as those mediating the actions of excitatory amino acids and opioid peptides, also interact with dopamine and have been implicated in mechanisms of motivationally relevant processes (Churchill, Roques, \& Kalivas, 1995; Pierce, Bell, Duffy, \& Kalivas, 1996). Therefore, the localization of these receptors to precise morphological sites seems crucial to our understanding of the mechanisms underlying numerous behavioral effects (cf. reviews of Kalivas, Churchill, \& Klitenick, 1993, and Mogenson, Brudzynski, Wu, Yang, \& Yim, 1993). There are, however, discrepancies between neuroanatomical and pharmacological findings. Often, behavioral effects can only be explained by the presynaptic activation of receptors; however, ultrastructural studies have not, so far, identified axo-axonic synapses in the striatum, whereas presynaptic actions are well documented pharmacologically. There are also numerous mismatches between the location of receptors and their related synapses (Herkenham, 1987). Nevertheless, other mechanisms of action have been proposed, and it is now widely accepted that dopamine, and perhaps other neurotransmitters, can diffuse some distance from the site of their release to reach extrasynaptic receptor locations (Herkenham, 1987). Furthermore, ultrastructural studies have identified close appositions and other membrane-spanning structures, such as the puncta adhaerens, that may account for some interactions (see, e.g., Gracy \& Pickel, 1996; Gracy, Svingos, \& Pickel, 1997; Meredith, Ingham, Voorn, \& Arbuthnott, 1993; Sesack \& Pickel, 1990). Finally, an anatomical substrate for electrical transmission between cells has been described and appears to be regulated by dopamine (O'Donnell \& Grace, 1993a; also see O’Donnell, 1999).

Both families of dopaminergic receptors are found in nucleus accumbens, and the D1, D2, and D3 subtypes are found in both the shell and the core (Bardo \& Hammer, 1991; Bouthenet et al., 1991). Receptors belonging to the D1 and D2 subtypes decrease in density along a rostral-to-caudal gradient, and D2 receptors are denser in the core than in the shell, whereas D1 receptors are concentrated similarly in both territories (Bardo \& Hammer, 1991). The D2 receptor is present in equal proportions in dendrites/spines and axon terminals of GABAergic principal and local circuit neurons in the medial shell (Delle Donne, Sesack, \& Pickel, 1997).

Dopaminergic D3 receptors are reported to be denser in nucleus accumbens than in the dorsal striatum (Lévesque et al., 1995) and are densest over the islands of Calleja that line the medial and ventral borders of the shell (Bouthenet et al., 1991; Le Moine \& Bloch, 1996). Recent work has shown that up to one quarter of the principal neurons in the shell that contain substance $P$ also express both the D1 receptor and the D3 receptor; in the core, only $16 \%$ of these cells have both receptors (Le Moine \& Bloch, 1996). Considering the recent evidence for the reduction of D3 receptors in psychosis (Schmauss, Haroutunian, Davis, \& Davidson, 1993) and their activation by cocaine (Caine \& Koob, 1993), these receptors could potentially play a very important role in mediating the motivational state of individuals.

Opioid receptors, as defined with naloxone binding, form dense aggregates in the rostral and caudal core and overlap small zones enriched with enkephalinergic fibers (Jongen-Rêlo et al., 1993); they also coincide with small clusters of cells in the caudomedial shell at the septal pole (Herkenham et al., 1984). Behavioral studies ascribe the aversive and rewarding effects of opiates to precise neuroanatomical sites, where high densities of mu and kappa receptors are found (Bals-Kubik, Ableitner, Herz, $\&$ Shippenberg, 1993), and, recently, $\mu$-opioid receptors 
have been localized to dendrites and spines within dense enkephalinergic patches of the core (Svingos, Moriwaki, Wang, Uhl, \& Pickel, 1996).

Glutamatergic transmission in nucleus accumbens is mediated primarily by $\alpha$-amino-3-hydroxy-5-methyl-4isoxazoleproprionic acid (AMPA)/kainate receptors. The $N$-methyl-D-aspartate (NMDA) receptors seem to be activated in the absence of $\mathrm{GABA}_{\mathrm{A}}$ receptor-mediated inhibition (Pennartz, Boeijinga, \& Lopes da Silva, 1990). There is a greater density of NMDA receptors in nucleus accumbens, relative to the dorsal striatum (Maragos, Penney, \& Young, 1988); in the shell, they are found primarily in dendrites but also exist in axons and terminals and occasionally in astrocytes, and they are found in $17 \%$ of somata and dendrites of NOS-immunorective neurons (Gracy \& Pickel, 1996, 1997; Gracy et al., 1997). The core and rostral pole have not as yet been investigated. The compartmental distribution of AMPA receptors in nucleus accumbens is not fully known, but activity at these receptors has been shown for both shell and core territories (Kelley \& Swanson, 1997; Pennartz et al., 1990 ). Both AMPA and NMDA receptors play a role in learning and memory. For example, NMDA receptors in the accumbal core seem to be preferentially involved in learning (Maldonado-Irizarry \& Kelley, 1995), and AMPA receptors in the caudomedial shell play a direct role in feeding behavior (Kelley \& Swanson, 1997).

\section{SYNAPTIC FRAMEWORK}

The neural substrate subserving adaptive behaviors is complex and is dependent not only on the neurochemical compartmentation and extrasynaptic activation of receptors but also on the different structural elements that interact synaptically to form microcircuits. The basic structural unit, whether in shell or core, is the mediumsized, densely spiny projection neuron. The function of such a neuron in vivo is likely to depend on the source of its extrinsic inputs, its synaptic relationships with neighboring cells, especially those involved in local circuits, and its ultimate targets. Hence, it is not enough to know that there is a synaptic input from the ventral subiculum in the hippocampus to the projection neurons of the caudomedial shell (Totterdell \& Smith, 1989), but it is also crucial to understand that this input makes asymmetrical contacts with the heads of spines of these neurons, as well as synapses with local neurons that, in turn, form symmetrical synapses with proximal dendrites of the projection cells. Thus, the outflow from these neurons may be regulated directly (Yang \& Mogenson, 1984) or indirectly through local circuit neurons (Pennartz \& Kitai, 1991).

Major excitatory inputs to nucleus accumbens originate in the hippocampus, the entorhinal cortex, the basal amygdala, and the medial and lateral subdivisions of the prefrontal cortex, and project to the nucleus topographically (Brog et al., 1993; Groenewegen et al., 1987; Johnson, Aylward, Hussain, \& Totterdell, 1994; Sesack \& Pickel, 1992; Totterdell \& Meredith, 1997; Wright, Bei- jer, \& Groenewegen, 1996). The full extent of these projections is not known, but, in the case of subicular input, even following extensive lesions, it would seem that no more than $30 \%$ of all excitatory terminals in the caudomedial shell of the nucleus are found to be degenerating (Sesack \& Pickel, 1990; Totterdell \& Smith, 1989). The projection neurons that receive hippocampal input are thus also postsynaptic to a number of other sources: some that could also be excitatory, and others that make symmetrical synaptic contacts and are presumably inhibitory. Axons from cortical centers use an excitatory amino acid, presumably glutamate, as neurotransmitter and form asymmetrical synaptic contacts (Figures 4B and 4C) primarily with spines of principal neurons (Johnson, Aylward, Hussain, \& Totterdell, 1994; Meredith, Pennartz, \& Groenewegen, 1993; Meredith \& Wouterlood, 1990; Sesack \& Pickel, 1992; Totterdell \& Meredith, 1997). The overwhelming majority of cortical terminals contact the heads of spines (Table 1); indeed, prefrontal and entorhinal fibers terminate almost exclusively on spines (Sesack \& Pickel, 1992; Totterdell \& Meredith, 1997). However, $10 \%-15 \%$ of hippocampal input to the medial shell and $8 \%$ of amygdalar input to the core and the shell synapse with dendrites (Table 1; Johnson et al., 1994; Meredith et al., 1990; Totterdell \& Smith, 1989). Axon terminals of hippocampal fibers at the septal pole sometimes form axosomatic contacts with projection neurons and, occasionally, with aspiny interneurons (Meredith \& Wouterlood, 1990; Meredith et al., 1990; Totterdell \& Smith, 1989).

Another major source of excitation to accumbal cells is from centers in the midline or intralaminar thalamus (Berendse \& Groenewegen, 1990). Axons from these centers form asymmetrical contacts with dendrites and spines in roughly equal proportions (Meredith \& Wouterlood, 1990). At the septal pole in the medial shell, axosomatic inputs are rare but include contacts with presumed interneurons (i.e., cells with an indented nuclear envelope). Furthermore, midline thalamic terminals provide a major proximal innervation to cholinergic neurons, where they form axodendritic and axosomatic contacts with ChAT-immunoreactive elements (Meredith \& Wouterlood, 1990).

Dopamine, which is more plentiful in nucleus accumbens than in the dorsal striatum (Fonnum \& Walaas, 1981), provides a major source of symmetrical synaptic input to accumbal neurons. The dopaminergic inputs to accumbens arise primarily from $\mathrm{A} 8$ and $\mathrm{A} 10$ cell groups in the midbrain and project densely following a medial-to-lateral topography (Domesick, 1981; Groenewegen \& Russchen, 1984). Axons from the A8 group project more laterally in the shell than those from A10 cells, and projections from the A9 cells are restricted to the core and lateral shell (Brog et al., 1993). Noradrenergic projections from the locus ceruleus are concentrated in the shell (Berridge, Stratford, Foote, \& Kelley, 1997); serotonergic inputs, which are distributed to both core and shell, originate from cells in the periaqueductal gray and the dorsal 

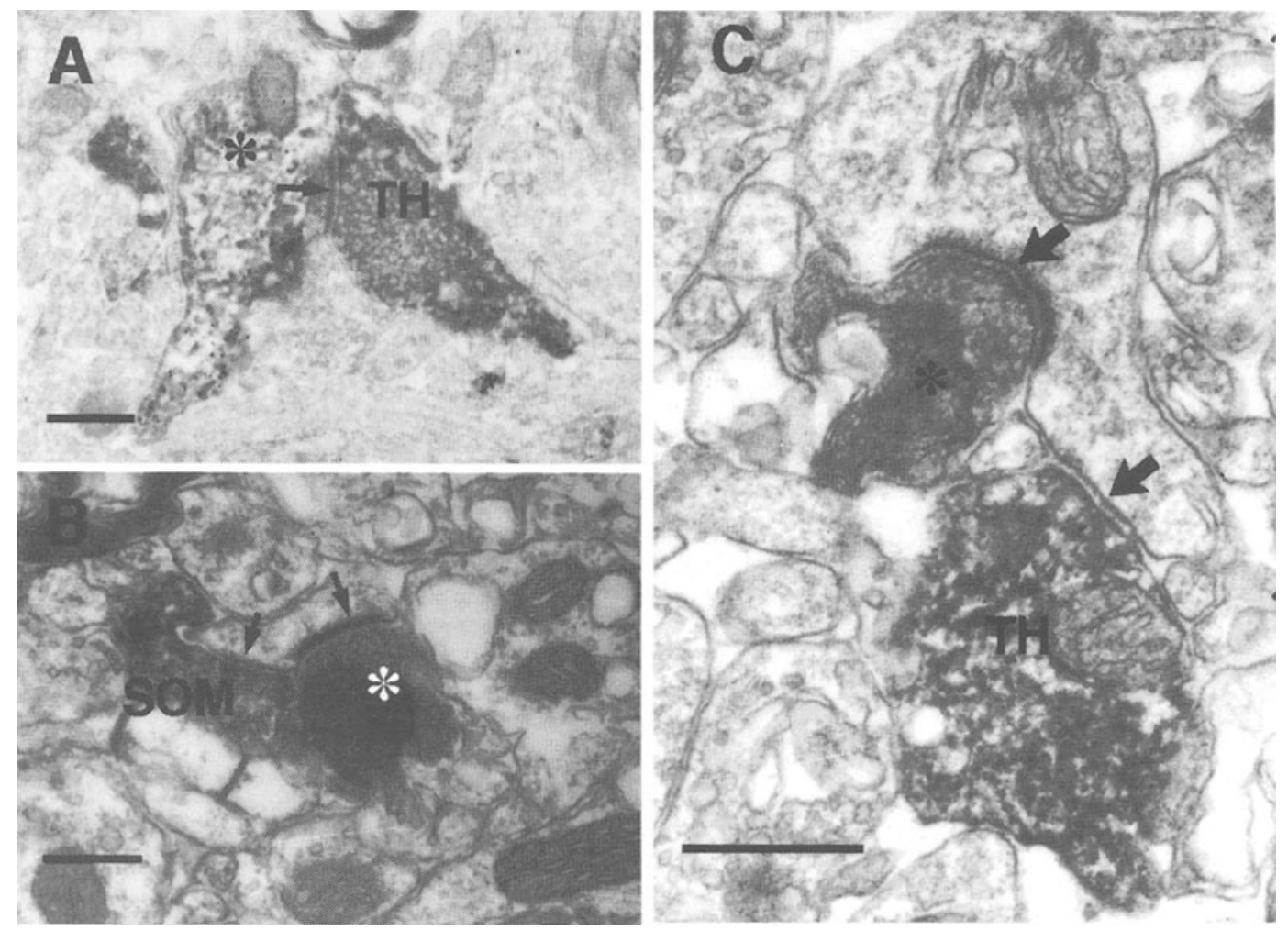

Figure 4. Electron micrographs that show the following: (A) A TH-immunoreactive terminal making an asymmetrical contact (arrow) with a dendrite of a medium spiny neuron (asterisk) that projects to the VTA. The medium spiny, principal neuron has been intracellularly filled with the fluorescent dye, Lucifer yellow, immunoreacted, and the DAB reaction product silver-gold intensified (small particles over the dendrite). (B) A somatostatin immunoreactive bouton (presumably from a somatostatin/NOS/NPY interneuron) in symmetrical synaptic contact (arrow) with a spine in the shell region that also receives synaptic input from a bouton on a fiber from the amygdala (asterisk). This bouton, which is degenerating as the result of a lesion of the amygdala, makes an asymmetric synaptic contact (arrow) with the spine. (C) A bouton (asterisk), degenerating following a lesion of the hippocampal input to the nucleus accumbens and making an asymmetrical synaptic contact (arrow), converges with a TH-immunoreactive terminal making a symmetrical synaptic contact (arrow) onto the same postsynaptic target. Scale bar are equal to $0.5 \mu \mathrm{m}$.

and median raphé (Li, Rao, \& Shi, 1989; Van Bockstaele \& Pickel, 1993; Vertes, 1991).

Antibodies to dopamine itself proved hard to produce initially, and many studies have employed antibodies to $\mathrm{TH}$ - the rate-limiting enzyme in the production of dopamine. This approach is sometimes criticized, since TH is also present in noradrenergic and adrenergic neurons; however, experience has shown that, in the striatum at least, the TH antibodies are markers of dopaminecontaining axons, not noradrenergic fibers (Totterdell \& Smith, 1989). Dopaminergic fibers in nucleus accumbens innervate both spiny and aspiny neurons in the shell (Figure 4A) and core (Tables 1 and 2), but their synaptic arrangements differ with respect to location (Zahm, 1992). It was first noted (Freund, Powell, \& Smith, 1984) in the dorsal striatum that dopaminergic terminals form symmetrical inputs to spine necks, whereas asymmetrical specializations are found on the heads. Dopaminergic endings also make symmetrical, axodendritic synapses proximal to excitatory inputs, a geometric arrangement that would suggest that dopamine is in an ideal position to modulate the excitatory afferent input (Freund et al., 1984). At the septal pole of nucleus accumbens, the major proportion of TH-labeled terminals contact dendrites (Figures 4A and 4C) and, often, proximal shafts, whereas in the core, as in the dorsal striatum, the majority of THpositive axons form axospinous junctions with the necks of spines (Table 1; Meredith, Pennartz, \& Groenewegen, 1993; Zahm, 1992). The preferred arrangement with dendritic shafts in the shell could account for the more pronounced effects of dopamine on shell neurons ( $\mathrm{O}^{\prime}$ Donnell \& Grace, 1993a; Pennartz, Dolleman-Van der Weel, Kitai, \& Lopes da Silva, 1992) and presumably underlies the ability of stress to alter dopamine flow in the shell but not the core (Deutch \& Cameron, 1992; Kalivas \& Duffy, 1995).

The convergence of inputs onto the same postsynaptic target has important implications for the physiological function of accumbal circuits, especially when the proximal-distal arrangement of the inputs is taken into 
Table 1

Synaptic Targets (Spine, Dendrite, and Soma) for Extrinsic and Intrinsic Inputs to Nucleus Accumbens' Core and Shell

\begin{tabular}{|c|c|c|c|c|c|c|c|}
\hline & \multicolumn{3}{|c|}{ Nucleus Accumbens } & \multicolumn{3}{|c|}{ Septal Pole (Medial Shell) } & \multirow[b]{2}{*}{ Reference } \\
\hline & Spine & Dendrite & Soma & Spine & Dendrite & Soma & \\
\hline \multicolumn{8}{|l|}{ Glutamate } \\
\hline Hippocampus & & & & +++ & ++ & \pm & Meredith et al. (1990) \\
\hline Amygdala & +++ & $+($ core $)$ & 0 & +++ & + & 0 & Johnson, Aylward, \& Totterdell (1994b) \\
\hline Prefontal cortex & +++ & \pm (core) & 0 & & & & Sesack \& Pickel (1992) \\
\hline Midline thalamus & & & & ++ & +1 & + & Meredith \& Wouterlood (1990) \\
\hline \multicolumn{8}{|l|}{ Monoamines } \\
\hline Dopamine $(\mathrm{TH})$ & ++ & ++ (core) & \pm & ++ & +++ & \pm & Zahm (1992) \\
\hline $5-\mathrm{HT}$ & \pm & $+1+$ & 0 & & & & Van Bockstaele \& Pickel (1993) \\
\hline \multicolumn{8}{|l|}{ Opioids } \\
\hline Enkephalin & + & ++++ (core) & + & ++ & +++ & + & Meredith, Ingham, et al. (1993) \\
\hline Dynorphin & + & +++ & + & + & +++ & + & Van Bockstaele et al. (1994); Meredith et al. (1997) \\
\hline Substance $P$ & + & +++ & + & & & & Pickel et al. (1988) \\
\hline \multicolumn{8}{|l|}{ Interneurons } \\
\hline GABA & + & +++ (core) & ++ & + & $+++(+)$ & + & Johnson et al. (1994a) \\
\hline Paravalbumin & 0 & $++++($ core $)$ & ++ & & & & Totterdell \& Hussain (1996) \\
\hline Calretinin & + & +++ & + & & & & Totterdell \& Hussain (1996) \\
\hline Somatostatin & + & ++++ & \pm & & & & Johnson et al. (1994a) \\
\hline Acetylcholine & + & +++ & + & & & & Phelps \& Vaughn (1986) \\
\hline
\end{tabular}

Note-The following symbols represent the approximate percentages of terminals contacting the target: $+1+=76 \%-100 \% ;++=40 \%-75 \%$; $+=10 \%-39 \% ;+=3 \%-9 \% ; \pm=\leq 2 \%$ (rare contacts) $0=$ no contacts.

consideration. Table 2 summarizes the convergent arrangements that have been reported to date. Terminals of hippocampal, prefrontal, and amygdalar axons each converge with TH-immunolabeled, presumably dopaminergic, endings onto the same postsynaptic structure (i.e., spine or dendrite; Figure $4 \mathrm{C}$ and Table 2). In the medial shell, hippocampal and TH-positive terminals both contact the same interneuron or the same spine or dendrite of medium spiny projection neurons (Figure $4 \mathrm{C}$; Sesack \& Pickel, 1990; Totterdell \& Smith, 1989). In the core and shell, amygdalar endings converge with TH-immunoreactive boutons on the same spiny projection cell, with the cortical terminal generally making an axospinous contact and the dopaminergic bouton, an axodendritic synapse (Johnson, Aylward, Hussain, \& Totterdell, 1994; Johnson, Aylward, \& Totterdell, 1994b). Finally, in the core, medial prefrontal inputs (prelimbic, infralimbic areas) converge with TH-immunolabeled terminals onto spines (Sesack \& Pickel, 1990).

Recent work in the septal pole of the medial shell has shown that NMDA receptors are colocalized with TH in axons and terminals (Gracy \& Pickel, 1996), an arrangement that could subserve the presynaptic regulation of dopamine transmission. Such an arrangement may provide the basis, at least in part, for the rewarding effects of cocaine, since repeated administration of this psychostimulant augments dopamine transmission in the shell, an event further enhanced by NMDA agonists (Cervo \& Samanin, 1995; Pierce \& Kalivas, 1995).

Another important source of symmetrical synaptic input to both core and shell neurons comes from the axon collaterals of projection neurons. Their synaptic termi-

Table 2

Neural Elements in Nucleus Accumbens That Have Been Reported to Receive Convergent Terminals

\begin{tabular}{lcccc}
\hline $\begin{array}{c}\text { Source of } \\
\text { Terminals }\end{array}$ & $\begin{array}{c}\text { Principal Neuron } \\
\text { (Medium Spiny) }\end{array}$ & $\begin{array}{c}\text { Local Circuit } \\
\text { Neuron (Aspiny) }\end{array}$ & $\begin{array}{c}\text { Dendrite of } \\
\text { Unknown Origin }\end{array}$ & Reference \\
\hline $\begin{array}{l}\text { TH and prefrontal } \\
\text { cortex in core }\end{array}$ & $\mathrm{X}$ & $\mathrm{X}$ & $\mathrm{X}$ & Sesack \& Pickel (1992) \\
$\begin{array}{l}\text { TH and Hippocampus } \\
\text { in shell }\end{array}$ & $\mathrm{X}$ & $\mathrm{X}$ & Totterdell \& Smith (1989) \\
$\begin{array}{l}\text { Somatostatin and } \\
\text { basolateral } \\
\text { amygdala in shell }\end{array}$ & $\mathrm{X}$ & $\mathrm{X}$ & $\mathrm{X}$ & Johnson et al. (1994) \\
$\begin{array}{l}\text { TH and amygdala } \\
\text { in core and shell }\end{array}$ & $\mathrm{X}$ & $\mathrm{X}$ & & Johnson et al. (1994b) \\
$\begin{array}{l}\text { GABA and basolateral } \\
\text { amygdala in shell }\end{array}$ & $\mathrm{X}$ & $\mathrm{X}$ & $\mathrm{X}$ & Meredith \& Chang (1994) \\
$\begin{array}{l}\text { Enkephalin and } \\
\text { acetylcholine in core }\end{array}$ & $\mathrm{X}$ & $\mathrm{X}$ & $\begin{array}{l}\text { Van Bockstaele et al. (1994) } \\
\text { Pickel et al. (1988) }\end{array}$ \\
$\begin{array}{l}\text { TH and Dynorphin } \\
\text { TH and Substance P }\end{array}$ & $\mathrm{X}$ &
\end{tabular}

Note-Convergence is indicated by $X$ 

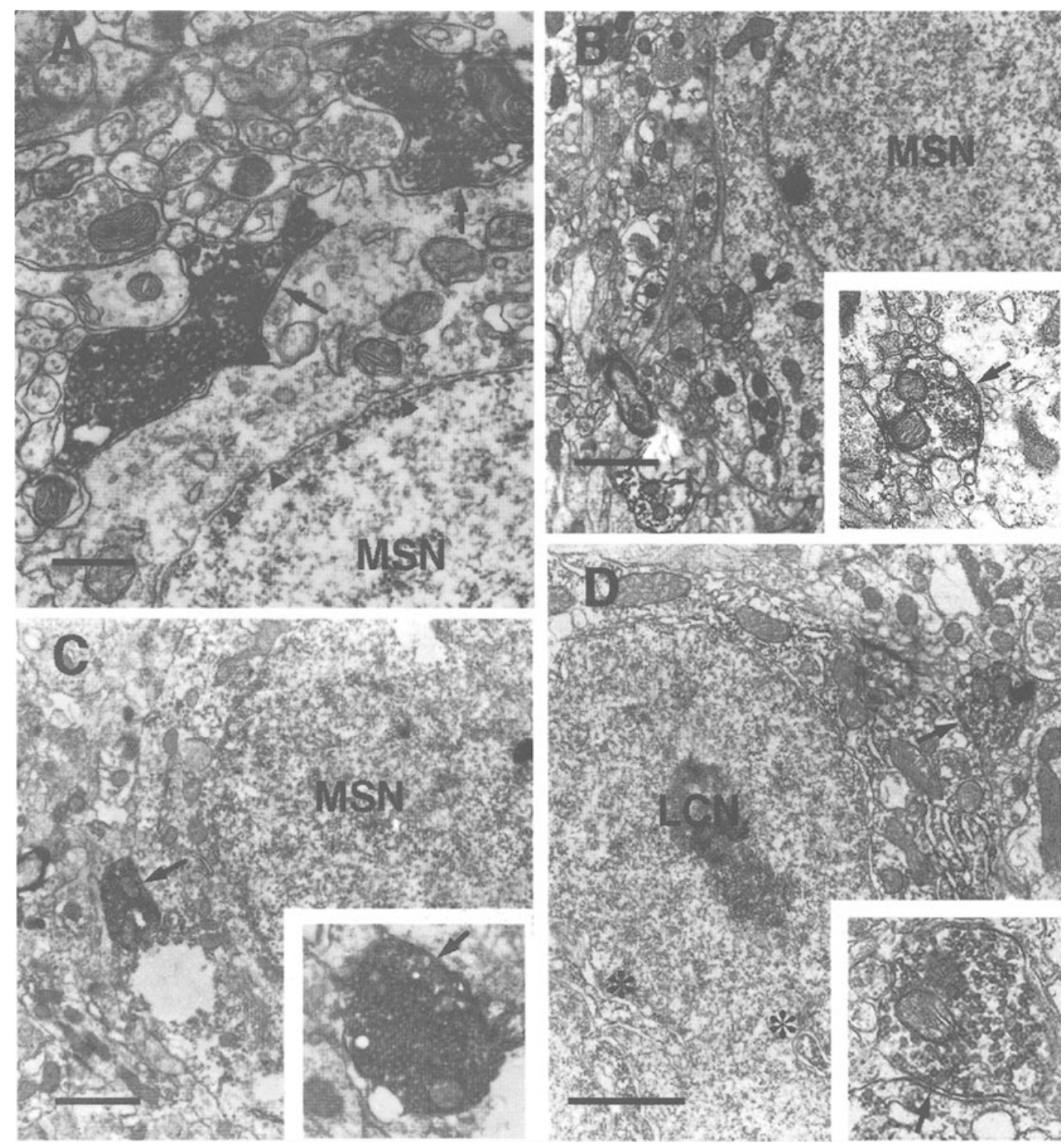

Figure 5. Electron micrographs illustrating the following: (A) Two enkephalinergic, symmetrical contacts (arrows) with a medium spiny neuron (MSN) in the core (note the smooth nuclear envelope [filled triangles], typical of projection neurons). (B) PV-positive terminal contacting (arrow) a MSN. Inset shows an enlarged view of the synaptic bouton and arrow points to the symmetrical specialization. (C) Calretinin-immunoreactive bouton contacting (arrow) a MSN. The immunolabeled terminal is enlarged in inset and arrow points to the symmetrical synapse. (D) PVimmunolabeled terminal contacting a PV-immunoreactive local circuit neuron (LCN) (note the deep indentations in the nuclear envelope [asterisks] indicative of its interneuronal status). Inset shows the enlarged PV-positive terminal and its symmetrical specialization. Scale bars: A, $1 \mu \mathrm{m} ; \mathrm{B}-\mathrm{D}, 2 \mu \mathrm{m}$.

nals contain GABA and either enkephalin or substance $P$ and dynorphin. Networks of their local axons are concentrated in restricted parts of the nucleus - that is, large, dense "patches" of enkephalinergic fibers are located in the rostral core, smaller dense "patches" are found in the caudal core (Figure $2 \mathrm{~A}$ ), and substance $\mathrm{P}$ or dynorphinergic (Figure 2B) fibers appear to be densest at the septal pole. Local connections have been studied anatomically using antibodies against enkephalin, dynorphin, and substance P (Meredith, Egan, Tipper, Wong, \& Hyde, 1997; Meredith, Ingham, et al., 1993; Pickel et al., 1988; Van Bockstaele et al., 1994), and physiologically with intracellular recordings (Chang \& Kitai, 1986; O'Donnell \& Grace, 1993b). These principal cells are known to contact local circuit neurons and their medium-sized spiny neighbors (Figure 5A), but autaptic synapses do not appear to occur (O'Donnell \& Grace, 1993b). Several studies have suggested that the local collaterals are im- 
portant for lateral inhibition (Chang \& Kitai, 1985) by presumably "sharpening" the responses to the cortical inputs (Pennartz et al., 1993; Pennartz, Groenewegen, \& Lopes da Silva, 1994).

Local terminals of enkephalinergic, dynorphinergic, and substance P-positive neurons primarily contact dendrites, but they also synapse with spines and perikarya of other principal neurons (Figure 5A and Table 1). Enkephalinergic terminals form significantly more axospinous contacts in the shell $(19 \%)$ and in caudal enkephalin-rich patches $(17 \%)$ than in the rest of the core, where only $8 \%$ of the endings terminate on spines (Meredith, Ingham, et al., 1993). Dynorphinergic terminals do not show such a bias: Axodendritic contacts in both shell and core comprise roughly $75 \%-80 \%$ of the synapses, and axospinous junctions make up 4\%-9\% in either territory (Meredith \& Tipper, 1996). Eight percent of substance P-positive terminals contact spines (Pickel et al., 1988). Enkephalinergic terminals also form contacts with ChAT-positive interneurons, but these are rare and have only been reported in the core (Meredith \& Chang, 1994).

The anatomical localizations of the opioid receptors have been little studied. In the core, mu opioid receptors are found primarily in dendrites and spines (Svingos et al., 1996). In the shell, a small percentage of mu opioid receptors are colocalized in the same dendrite or axon with the R1 subunit of the NMDA receptor (Gracy et al., 1997); the delta opioid receptors are concentrated in axons and terminals, which primarily form symmetrical synapses (Svingos, Clarke, \& Pickel, 1998). Kappa receptor localization has yet to be examined. Dopamine regulates enkephalin and dynorphin and their receptors, since dopamine depletion or chronic blockade of dopaminergic receptors are known to upregulate enkephalin but have mixed effects on dynorphin in nucleus accumbens (Egan et al., 1994; Meredith et al., 1997; Voorn, Docter, Jongen-Rêlo, \& Jonker, 1994). Moreover, disruption of the dopamine supply alters the effects of opioids on locomotion (Churchill, Klitenick, \& Kalivas, 1998; Churchill et al., 1995) and raises levels of excitatory amino acids (Lannes \& Micheletti, 1994). The intra-accumbal stimulation of enkephalinergic or mu opioid receptors in the dopamine-depleted nucleus accumbens significantly increases motor activity, an action that seems to occur via pathways other than those flowing through the ventral tegmental area (Churchill et al., 1998). Furthermore, blockade of dopamine receptors sensitizes rats to the reinforcing effects of heroin (see Kalivas et al., 1993, for review). The anatomical substrate for this sensitization could involve the dopaminergic input to enkephalinergic neurons and also receive cortical contacts or the dopaminergic input to dendrites that contain opioid and NMDA receptors (Gracy et al., 1997). Such arrangements presumably occur on principal neurons but may also be on interneurons, such as those containing NOS/NPY, which receive inputs (dopaminergic?) from the ventral tegmental area (Totterdell \& McFarlane, 1996), contain the R1 sub- unit of the NMDA receptor (Gracey \& Pickel, 1997), and presumably contact opioid-containing projection neurons.

The connections of the interneurons in nucleus accumbens have not been studied extensively, but the role of a particular population is likely to reflect their compartmental distribution, their synaptic interactions with projection and other local circuit neurons, and their relationship with extrinsic afferent inputs. Physiologically, the interneurons are likely to be diverse considering that, in the dorsal striatum, fast spiking, low-threshold spiking, and long-duration after-hyperpolarizing cells have been identified (Kawaguchi, 1993). Limited work (Pennartz \& Kitai, 1991; Pennartz \& Lopes da Silva, 1994) in nucleus accumbens show that local circuit cholinergic neurons modulate synaptic responses and membrane properties of principal neurons and strongly attenuate both excitatory postsynaptic potentials (EPSPs) and inhibitory postsynaptic potentials (IPSPs) in the nucleus.

In the dorsal striatum, Kawaguchi (1993) found that fast-spiking cells are immunoreactive for PV. Since fornix stimulation results in a monosynaptic EPSP and a disynaptic IPSP that is mediated via both glutamate and GABA in nucleus accumbens, it has been suggested that the PV-containing interneurons are the substrate of feedforward inhibition (Pennartz \& Kitai, 1991). Parvalbuminpositive terminals form symmetrical contacts with principal cells, providing inputs predominantly onto somata (Figure 5B) and proximal dendrites (Table 1; Hussain et al., 1996). Synaptic contacts have been reported between inputs from the basolateral amygdala and PV neurons, although it is likely that the postsynaptic PV neurons in this study were from a very caudal and ventral part of the nucleus (Sadikot et al., 1996). Parvalbumin-positive neurons also receive PV input (Figure 5D; Hussain et al., 1996; Sadikot et al., 1996), presumably from interneurons but possibly also from extrinsic sources, such as the ventral pallidum, where PV has been reported in the GABAergic projection cells (Sadikot et al., 1996). In the dorsal striatum, PV neurons receive excitatory input from the cortex onto all parts of the PV neuron examined (Bennett \& Bolam, 1994), and it is possible that PV neurons are the site of convergence of a number of different cortical inputs. However, this has yet to be investigated for ventral parts of the striatum.

Although it is known that calretinin-immunoreactive neurons are postsynaptic to boutons making asymmetrical synaptic contacts (Hussain et al., 1996), as yet no source for these afferent terminals has been identified. Sadikot et al. (1996) did not find input from the basolateral amygdala. These neurons also receive symmetrical synaptic inputs from calretinin-immunoreactive boutons and establish symmetrical and asymmetrical contacts with medium-sized, densely spiny projection neurons (Figure 4C and Table 1; Hussain et al., 1996).

In the dorsal striatum, NADPH-diaphorase reactive neurons have been shown to receive dopaminergic input (Fujiyama \& Masuko, 1996); in the accumbal shell, NOSimmunoreactive neurons have been found to be postsy- 
naptic to terminals originating from neurons in the ventral tegmental area (Totterdell \& McFarlane, 1998). Striatal neurons containing NADPH-diaphorase are also immunopositive for NOS and GABA and probably contain the neuropeptides, somatostatin and NPY (Kawaguchi \& Kubota, 1995). Dorsal striatal NPY neurons receive direct input from the cortex (Vuillet, Kerkerian, Kachidian, Bosler, \& Nieoullon, 1989), but a cortical input has not yet been confirmed for these neurons in accumbens. The majority of somatostatin-immunoreactive boutons make symmetrical synaptic contacts (Figure 4B) with dendrites $(72 \%)$, some of which are large and presumably proximal, and spines $(27 \%)$, but occasionally with somata $(1 \%)$, percentages that do not differ between core and shell (Table 1; Johnson et al., 1994b). These results suggest that much of the output of these neurons is directed to the projection neurons and also converge with inputs from the amygdala onto spines of medial shell projection neurons (Figure 4B). Some somatostatin terminals may also reach other populations of interneurons.

Cholinergic neurons in the medial shell primarily form symmetrical axodendritic contacts, often with projection neurons. About one quarter of the terminals end on spines, and some of these synapses have asymmetrical specializations (Meredith \& Wouterlood, 1990). Cholinergic cells receive inputs from midline thalamic axons onto proximal dendrites and perikarya but only rare inputs from the hippocampus, which form more distal contacts. They also receive axodendritic synapses from other ChAT-positive terminals. In the dorsal striatum, cholinergic neurons receive a dopaminergic input, and acetylcholine release is under dopaminergic control (Dimova, Vuillett, Nieoullon, \& Kerkerian-Le Goff, 1993; Lehman \& Langer, 1983). However, there is evidence in nucleus accumbens that dopamine and acetylcholine can act independently, especially at caudal levels (Henselmans \& Stoof, 1991). Although synaptic contacts between these two elements have not yet been recorded, the pattern of local plexuses of cholinergic fibers matches that of the dopaminergic innervation (Meredith, Pennartz, \& Groenewegen, 1993), and TH-immunoreactive fibers have been seen to contact ChAT-immunolabeled neurons in the dorsal striatum (Dimova et al., 1993). Moreover, ChATpositive neurons, contain both dopaminergic D1 and D2 receptor mRNA (Jongen-Rêlo, Docter, Jonker, \& Voorn, 1995). Principal neurons also contain both dopaminergic D2 and muscarinic receptors (Delle Donne et al., 1997; Sugita, Uchimura, Jiang, \& North, 1991) and have been shown in independent studies to receive dopaminergic and cholinergic inputs (Meredith \& Chang, 1994; Voorn et al., 1986). Finally, dopamine and acetylcholine can interact to influence locomotion, in that cholinergic stimulation potentiates dopamine-stimulated locomotion (De Belleroche \& Gardiner, 1982), and dopamine receptor blockade attenuates cholinergic hyperactivity (Austin \& Kalivas, 1988).

\section{MICROCIRCUITS IN BEHAVIOR}

\section{Structural Framework Subserving Adaptive Behaviors}

Although there is abundant information on the role of the nucleus accumbens in a wide range of behaviors, little of this is presented within the anatomical framework of the nucleus. Pharmacological and lesion studies, with a few notable exceptions (see, e.g., Churchill et al., 1998), seldom take account of the core and shell divisions, and the rostral pole is only rarely considered, although there is a wealth of anatomical data to suggest that these regions are unlikely to function in the same way in different cognitive behaviors. When trying to establish precise circuitry, the compartmental distribution of afferents is particularly important. For example, afferents arising from the amygdala make connections in both core and shell regions (Johnson et al., 1994b), whereas those from the ventral subiculum of the hippocampal formation terminate in medial parts of the shell (Groenewegen et al., 1987; Meredith, Pennartz, \& Groenewegen, 1993; Totterdell \& Smith, 1989).

The input to the nucleus accumbens most extensively studied in a behavioral context is undoubtedly the dopaminergic input arising from neurons in the midbrain. Dopaminergic afferents reach all parts of the nucleus accumbens, although there are differences between the core and septal pole and in the precise topography of synaptic connections (Zahm, 1992; Zahm \& Brog, 1992). The changes in firing pattern of midbrain neurons, between bursts and regular spiking, probably encode different information (Grace, 1991). Behaviorally relevant stimulation causes short-term increases in cell firing and, thus, phasic release of dopamine; tonic release, controlled by afferents from the prefrontal cortex, regulates the intensity of phasic firing by setting the background level of both dopaminergic receptors, auto- and postsynaptic (Grace, 1991; O'Donnell \& Grace, 1993a). The fact that dopaminergic afferents apparently contact all projection neurons (Totterdell \& Smith, 1989) would suggest that the role of dopamine is likely to be modulatory and possibly independent of the source of the excitatory input to the postsynaptic cell.

It has been proposed that dopamine in the nucleus accumbens plays an important role in determining responses to novelty and stress (Burns, Arnett, Kelley, Everitt, \& Robbins, 1996). Dopamine activity is increased both in the prefrontal cortex and the nucleus accumbens in response to footshock or restraint stress (Sudha \& Pradhan, 1995) and in the accumbens during execution of a behavioral response to a stressor (Robbins \& Everitt, 1992). Dopamine elevations in accumbens are apparently not due to increases in firing rate of the midbrain neurons, but they may result from interactions between the prefrontal cortical afferents and dopamine-containing terminals (Doherty \& Gratton, 1996). The influence of the prefrontal cortical input on the accumbens' dopaminer- 
A. NOVELTY (SHELL)

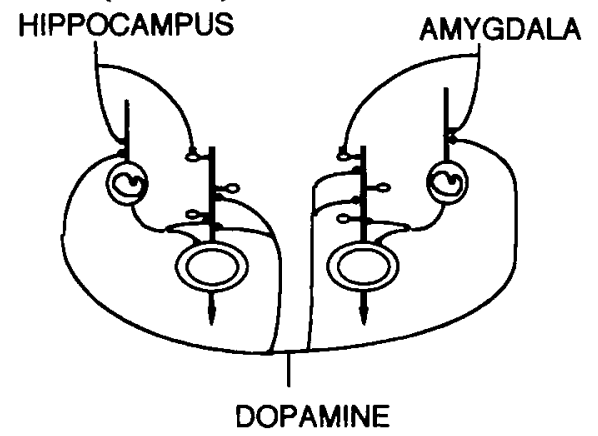

\section{B. SENSITIZATION}
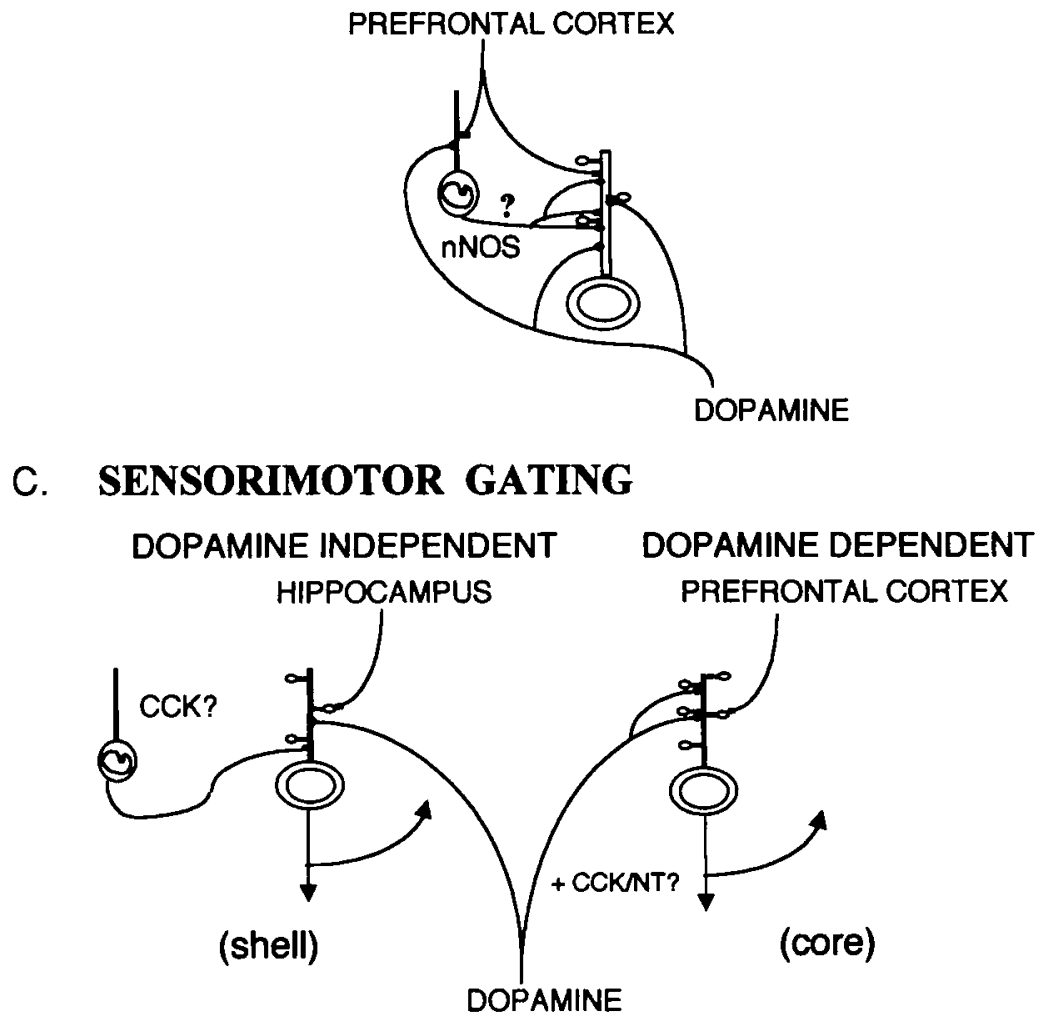

Figure 6. Hypothetical, simplified synaptic frameworks subserving motivationally related behaviors. See the Appendix for details.

gic response to stress seems to be specific to the shell region (Doherty \& Gratton, 1996; Lacroix, Broersen, Weiner, \& Feldon, 1998), where prefrontal cortical glutamatergic afferents make synaptic contacts with dendritic spines of projection neurons and dopaminergic input contact the dendritic shafts of the same neurons. Both dopaminergic and glutamatergic inputs probably contact local circuit neurons as well, and these in turn form synaptic contacts with the necks of spines, each of which also receives an excitatory input (Figure 4B; Johnson et al., 1994b), thus providing a possible site to modulate dopa- mine release. Although much of the neurotransmission within the nucleus accumbens depends on AMPA receptors, NMDA receptors are important in potentiating fast excitatory responses from the prefrontal cortex to the accumbens (Meredith, Pennartz, \& Groenewegen, 1993; O'Donnell \& Grace, 1995; Pennartz et al., 1994). Specific to the shell is the presynaptic distribution of NMDA receptors on dopaminergic terminals (Gracy \& Pickel, 1996), which may well provide the site for modulation of dopamine release by prefrontal cortical afferent terminals. These anatomical features may underlie the specific 
influence of the prefrontal cortex on dopamine release in the nucleus accumbens in response to stress (Kalivas \& Duffy, 1995).

Elevations of dopamine in accumbens are also reported in relation to the exposure of rats to novelty (Figure 6A). In a novel environment, rats show increases in locomotor activity (Burns et al., 1996), and the catecholaminergic signal in the prefrontal cortex and shell of the nucleus accumbens is elevated (Rebec, Grabner, Johnson, Pierce, \& Bardo, 1997). Both basolateral amygdalar and accumbal lesions increase locomotor activity, whereas prefrontal cortical lesions have no effect, and subicular lesions decrease locomotor activity (Figure 6A; Burns et al., 1996). There are also differences between these cortical afferents in the control of food neophobia (Burns et al., 1996). Rats do not like new foods, but this dislike is attenuated by lesions of the basolateral amygdala or the hippocampus, whereas lesions of the prefrontal cortex affect only initial food choice and latency to begin eating. Excitotoxic lesions of accumbens increase activity generally and decrease neophobia in a comparable way to hippocampal lesions. These experiments led Burns et al. to suggest specific cognitive roles for the afferents to the nucleus accumbens. Mesolimbic dopamine may thus produce a gain-amplification in behavioral responding, but it may also participate in switching and response selection. The basolateral amygdala relays affective information and may be involved in the fearful effects of the novel food rather than its novel taste (Burns et al., 1996). Increased locomotor activity means less fear of the new environment. Ventral subicular lesions may produce a weakened impact of novelty; thus, food neophobia is reduced, and explorative locomotor activity in a novel environment is reduced. Meanwhile, the prefrontal cortex is involved in detection of novelty.

These observations are particularly interesting since they highlight the point that even circuits with apparently similar synaptic connections within nucleus accumbens can have opposite effects on cognitive behavior. The prefrontal cortex, amygdala, and hippocampal axons all project to the shell (Brog et al., 1993), where they make synaptic connections with the spines of projection neurons (Figure 6A; Johnson et al., 1994b; Sesack \& Pickel, 1992; Totterdell \& Smith, 1989). In all cases, these excitatory inputs are associated with convergent dopaminergic afferents. However, stimulation of the subicular (hippocampal) input to the accumbens results in increased locomotion, whereas stimulation of the amygdala results in "freezing" (Mogenson et al., 1993). These two inputs may feed into functionally independent parallel circuits or possibly interact with the same population of projection neurons, with the inputs being differentially modified by interactions with certain interneuronal populations (Figure 6A). The amygdala apparently relays affective information (fear of novelty, association with reward), whereas the subiculum relays the inhibitory or excitatory effects of novelty on behavioral output (Burns et al., 1996). Behavioral and electrophysiological studies demonstrate convergence of these different limbic inputs onto single medium-sized, densely spiny neurons (Callaway, Hakan, \& Henriksen, 1991; O’Donnell \& Grace, 1995), but an anatomical confirmation of such arrangements is still awaited (Johnson, Aylward, \& Totterdell, 1994a). Early light microscopic studies tended to emphasize the segregation of the limbic inputs, although, in the case of inputs from the prefrontal cortex and amygdala, the patterns of overlap are proving significant (Wright \& Groenewegen, 1995).

These excitatory inputs from limbic cortices may also be differently modulated in the shell by arousal via the noradrenergic input from the locus coeruleus, stressrelated serotonin release, or acetylcholine from local interneurons at the septal pole (Berridge et al., 1997; Meredith \& Wouterlood, 1990; Van Bockstaele \& Pickel, 1993). This caudomedial part of the shell is a common target for prefrontal, hippocampal, and amygdala afferents and is where serotonin-immunoreactive boutons make synaptic contacts more frequently than in the core (Van Bockstaele \& Pickel, 1993). Despite physiological studies that show that 5HT depolarizes core neurons, the net result of 5HT action in the shell should be to inhibit the projection neurons (Van Bockstaele \& Pickel, 1993). The exact relationship between 5HT and interneurons is not clear.

A role has been proposed for the hippocampal-nucleusaccumbens pathway in learning. Ibotenate lesions of accumbens impair spatial discrimination learning, and dopamine depletion in the accumbens impairs working memory; reference memory errors are reported following the injection of glutamate antagonists into the nucleus accumbens (Schacter, Yang, Innis, \& Mogenson, 1989). Transfer of information from the hippocampus to the nucleus accumbens is not thought to involve NMDA receptors (Schacter et al., 1989), which is in line with the pharmacological/physiological data, although this receptor type is possibly relevant to learning (Pennartz et al., 1994). It has also been shown that chronic peripherally administered inhibition of NOS decreases the response of rats to novelty, possibly indicating a deficit in working memory (Cobb, Ryan, Frei, Guelgomez, \& Mickley, 1995). Although the NOS inhibitors may be acting via cortical regions, it is possible that the cortical input to the accumbens contacts NOS-containing local circuit neurons, which may then presynaptically downregulate transmitter release from the dopamine terminals or indirectly release the projection neurons from inhibition.

Perhaps an even more investigated behavioral relationship is that between dopamine in the nucleus accumbens and reward (Robbins \& Everitt, 1992), although it has been suggested that much of the data reflects a loss of mobility rather than a loss of motivation (Salamone, Cousins, \& Bucher, 1994). Accumbal dopamine, probably in the shell region, is involved in the maintenance of stimulusreward association (Everitt, Cador, \& Robbins, 1989; Spiegler \& Mishkin, 1981) and conditioned reinforcement (Gaffan \& Harrison, 1987) and is released in antic- 
ipation of reward (Robbins \& Everitt, 1992). There is also evidence, however, that dopamine is involved in the aversive aspects of motivation. As described earlier, dopamine is released in response to a wide range of stressful experiences, and dopamine antagonists have been shown to decrease active avoidance (Salamone, Kurth, McCullough, Sokolowski, \& Cousins, 1993) at doses that do not impair motor performance. It is possible that the appetitive consequences of dopamine activity are subserved by different subregions of accumbens from those that are activated in response to aversive stimuli. Both conditioned and primary aspects of reward also seem to require an input from the basolateral nucleus of the amygdala (Robbins \& Everitt, 1992). The amygdala has a specific role in associating stimuli with specific incentive properties of the reward and is important in determining the salience of the stimulus (Everitt et al., 1989; Robbins \& Everitt, 1992). Electrophysiological observations support the idea that amygdalar afferents and mesolimbic dopamine interact in the nucleus accumbens (Yim \& Mogenson, 1986), and ultrastructural work shows that these inputs converge onto the same principal neurons (Johnson et al., 1994).

Other limbic afferents of nucleus accumbens could also interact with the amygdalar input. It has been suggested (Weiner, 1990) that input from the rostral basolateral nucleus of the amygdala to the nucleus accumbens is involved in stimulus reinforcement, and this input innervates neurons primarily in the core region (Wright et al., 1996). Stimulation of NMDA receptors in the core is apparently crucial to the establishment of motor responses to reinforcing stimuli (Kelley, Smith-Roe, \& Holahan, 1997). The relationship between hippocampal and amygdalar inputs to the nucleus accumbens and their relative influences on cognitive behavior have been considered in some detail (Cools, Van den Bos, Ploeger, \& Ellenbroek, 1991). The proposed gating hypothesis, whereby input from the hippocampus impedes the reception of incoming information from the amygdala, suggests that these inputs might converge onto the same cells (O'Donnell \& Grace, 1995). These two sets of afferent fibers do indeed overlap in the medial striatum. The feed-forward circuitry via local interneurons (Pennartz \& Kitai, 1991) may also provide the anatomical substrate for such gating (see Figure 6A).

Dopamine release in the nucleus accumbens' shell is also related to the rewarding effects of drugs of abuse. There is a significant increase in accumbal dopamine in response to stimulation with cocaine (Bardo, 1998; J. S. Kim \& Levine, 1996), although it does seem that different drugs activate different circuits within this nucleus. In addition, NOS blockade significantly inhibits both cocaine- and morphine-induced conditioned place preference (H.-S. Kim \& Park, 1995; Kivastik, Rutkauskaite, \& Zharkovsky, 1996), suggesting a role in reward for NOScontaining interneurons in the shell. Some of these interneurons contain the R 1 subunit of the NMDA receptor (Gracey \& Pickel, 1997) and, thus, presumably receive input from cortical regions and make synaptic contacts with the projection neurons (Johnson, et al., 1994b). Nitric oxide is a readily diffusible gas that may act extrasynaptically, and it has been proposed as a retrograde messenger in the induction of long-term potentiation (Garthwaite, 1991) by reinforcing the strength of specific synaptic connections following repeated stimulation.

Repeated exposure to amphetamine, which produces behavioral sensitization (Figure 6B), results in longlasting structural changes (increased numbers of spines and/or longer dendrites) in neurons in both the prefrontal cortex and the nucleus accumbens (Robinson \& Kolb, 1997). Development of behavioral sensitization apparently depends on excitatory amino acid inputs to the nucleus accumbens (Pierce et al., 1996), the ventral tegmental area, or both, although different circuits might underpin the different behavioral elements of the development of sensitization to amphetamine (Wolf, Dahlin, $\mathrm{Hu}, \mathrm{Xue}, \&$ White, 1995). There is also a role for interaction between dopamine and the opioid peptides in such behavioral sensitization (Kalivas et al., 1993), since rats treated chronically with dopamine antagonists show greater reinforcement following systemically administered heroin. Enkephalinergic neurons that have had their dopaminergic input blocked certainly respond by upregulating the genes for the production of this peptide (Gerfen et al., 1990), a response that is presumably regulated by cortical inputs to these same neurons.

The subtle and complex nature of the behavioral deficits produced by interference with dopamine systems has led to the suggestion that dopamine is involved in sensorimotor function, the ability to use sensory information to regulate motor output (Figure 6C). Prepulse inhibition of acoustic startle (PPI), an operational measure of sensorimotor gating, is the normal reduction in startle reflex that occurs when a startling stimulus is preceded by a weak prepulse that does not itself elicit a response. Increasing dopamine function in the nucleus accumbens by a variety of means disrupts PPI (Wan, Caine, \& Swerdlow, 1996). Isolation rearing, which produces a hyperdopaminergic state in rats, also disrupts PPI (Wilkinson et al., 1994). Cholecystokinin, which may be coreleased with dopamine from fibers arising in the ventral tegmental area, is reported to potentiate apomorphine-induced disruption of PPI (Feifel \& Swerdlow, 1997), although this could be via intrinsic CCK neurons in the striatum (Tagaki et al., 1984).

PPI is regulated by both core and shell regions (Figure 6C; Kodsi \& Swerdlow, 1997). Interactions between the dopaminergic and glutamatergic inputs to the accumbens exert a complex influence over expression of PPI. Although PPI is disrupted by large (Bubser \& Koch, 1994) but not small (Lacroix et al., 1998) lesions of the prefrontal cortex, the glutamatergic afferents that have a very important control over PPI expression almost certainly originate in the hippocampus. PPI disruption following subconvulsive doses of NMDA injected into the hippocampus can be reversed by NMDA antagonists in the hippocam- 
pus or the accumbens (Klarner, Koch, \& Schnitzler, 1997; Wan et al., 1996) but not by dopamine D2 antagonists (Kretschmer \& Koch, 1997; Wan et al., 1996). The nonNMDA-induced disruptions of PPI are also dopamineindependent in the shell, although they are reversed by systemic haloperidol in the core (Figure 6C; Wan \& Swerdlow, 1996).

\section{Morphological Plasticity}

There is now good evidence that the structure and survival of neurons can be altered by dopamine and glutamate acting through their receptors and related second messenger systems. However, there is little information as to how dopamine or dopamine-glutamate interactions mediate structural change. Dopaminergic receptor stimulation controls the release of glutamate. At the septal pole, this process presumably occurs either presynaptically, since D2 receptors have been found on terminals that make asymmetrical contacts (Delle Donne et al., 1997), or postsynaptically through contacts situated close to asymmetrical inputs from the cortex (Sesack \& Pickel, 1992; Totterdell \& Smith, 1989) or, perhaps, via synapses with local circuit neurons (Hussain et al., 1996; Kawaguchi et al., 1995). While a certain level of glutamate is critical for synaptogenesis and plasticity and is crucial for the development of neuronal circuitry and in the formation and storage of memory (see Malenka \& Nicoll, 1993, for review), neurons can be damaged structurally by excessive levels (Michaels \& Rothman, 1990; Segal, 1995). Such alterations in structural geometry may be important factors in the production of motor abnormalities. Prinssen, Balestra, Bemelmans, and Cools (1994) have shown that dopaminergic stimulation of neurons in the caudomedial shell, but not the core, can augment chewing movements. Furthermore, removal of tonic excitatory inputs to this same region via blockade of the AMPA receptors enhances feeding activity (Kelley \& Swanson, 1997), suggesting that changes in the flow of glutamate to the shell are critical for oral movements. Chronic blockade of $\mathrm{D} 2$ receptors with neuroleptic drugs also raises levels of opioid peptides in the nucleus accumbens (Egan et al., 1994) and, in certain susceptible animals (i.e., those that develop abnormal orofacial movements), significantly increases the density of dynorphinergic axospinous contacts, at least in the caudomedial shell (Meredith et al., 1997). Since chronic blockade of D2 receptors elevates extracellular glutamate (See \& Chapman, 1994) and kappa receptors regulate striatal glutamate flow tonically (Rawls \& McGinty, 1998), it is likely that long-term dopamine receptor blockade also leads to a remodeling of dynorphinergic synapses, at least in the accumbens' medial shell.

We know that dendritic spines serve a neuroprotective function by acting as independent calcium compartments that respond to excitatory amino acid inputs rapidly and in a sustained manner (Segal, 1995). In nucleus accum- bens, dopamine depletion leads to a loss of spines in the core but not in the shell (Meredith, Ypma, \& Zahm, 1995). On the other hand, chronic administration of psychostimulants, such as amphetamine, produce an increase in the density of spines of both shell and core neurons (Robinson \& Kolb, 1997). The fact that the removal of dopamine acts differentially to decrease spine density leads us to believe that the mechanism(s) may be regionally specific. However, we would have also expected amphetamine to be site-specific, since repeated cocaine augments levels of dopamine in the shell but not the core (Pierce \& Kalivas, 1995; Sorg, Guminski, Hooks, \& Kalivas, 1995). Nevertheless, any change in the structural integrity of neurons, whether regionally specific or not, would alter circuit function and ultimately disturb the balance between pathways flowing out of the nucleus.

\section{CONCLUSIONS}

Underlying the complex behavioral functions of nucleus accumbens are structural frameworks of anatomical microcircuits. Although these frameworks can be described in terms of their neurons, synaptic connections, and receptors, it remains difficult to assign specific behavioral functions to a particular circuit. In any one part of the nucleus, topographically organized inputs from cortical and subcortical centers interact with an extensive dopaminergic innervation arising from the midbrain and no fewer than four different populations of interneurons. In addition, the multiple pathways flowing out from the nucleus to different targets mean that any one behavior could be subserved by more than one circuit at any one time.

At the septal pole, where the extended amygdala meets the striatum (Alheid \& Heimer, 1988), medium-sized densely spiny projection neurons have long expanses of dendrites, lined with inputs from extrinsic and intrinsic sources, as well as spines that receive cortical and thalamic synapses. In the core, projection neurons have spineladen dendrites with many of the same inputs. The anatomical substrate for presynaptic interactions may involve the activation of NMDA and/or D2 receptors found at extrasynaptic sites on axons and terminals, the intrinsic connections via interneurons or gap junctions (Delle Donne et al., 1997; Gracy \& Pickel, 1996; Gracy et al., 1997; Herkenham, 1987; Kawaguchi et al., 1995; O'Donnell \& Grace, 1993a). The anatomical differences in synaptic arrangements between these two territories are subtle. Proximal inputs to core neurons arise from intrinsic sources, and distal contacts are of extrinsic origin, whereas inputs to shell cells are mixed (i.e., of extrinsic and intrinsic origin regardless of the proximity to cell body). Moreover, enkephalinergic terminals end on fewer spines in the core than in the shell; dopaminergic inputs contact dendrites preferentially in the shell, and cortical endings in the core synapse less often on dendrites than in the shell. 
There are also shell/core differences in the distribution and density of interneurons, but little is known of territorial differences in their synaptic organizations.

There is now overwhelming evidence that, for a wide variety of behaviors (see, e.g., Figures $6 \mathrm{~A}, 6 \mathrm{~B}$, and $6 \mathrm{C}$ ), different circuits either in the same or in different parts of the nucleus become active. For example, the release of dopamine at the septal pole of the shell under behavioral conditions of reward, sensitization, and stress presumably relies on (1) the proximal arrangement of dopaminergic synapses in relation to cortical inputs to dendrites and spines, (2) the presence of NMDA receptors on THimmunoreactive axons and terminals, or (3) the synaptic organization of local circuit neurons that produce nitric oxide. Since locomotion is increased with stimulation of NMDA receptors (Kalivas et al., 1993) and the rewarding effects of cocaine are suppressed by blocking the synthesis of nitric oxide (Pulvirenti, Balducci, \& Koob, 1996), the NOS-positive interneurons in the shell may be key to understanding the behaviors associated with cocaine.

In the core, synaptic inputs from the prefrontal cortex or amygdala interact with dopaminergic endings primarily at the level of spines of the projection neurons. Stimulation of the glutamatergic AMPA receptors or increasing the dopaminergic activity in the core results in disruption of PPI (Wan \& Swerdlow, 1996). The net effect seems to reduce the activity of the projection cells, since blockade of their efferents, farther downstream, also disrupts PPI. Neurons in the core are also vulnerable to changes in dopamine: both its loss by dopamine-depleting lesions and its increase through chronic stimulation with amphetamine (Meredith et al., 1995; Robinson \& Kolb, 1997).

As we gather more neuroanatomical data on the synaptic framework of the shell and core circuits, the microcircuits underlying initiating and sustaining motivational and cognitive behaviors, are starting to unfold. We now know that, pharmacologically, behaviorally, and structurally, there are some fundamental differences in how the microcircuits of the accumbal core and the shell, especially at the septal pole, are built and operate.

\section{REFERENCES}

Al heid, G. F., \& HeImer, L. (1988). New perspectives in basal forebrain organization of special relevance for neuropsychiatric disorders: The striatopallidal, amygdaloid and corticopetal components of the substantia innominata. Neuroscience, 27, 1-39.

Austin, M. C., \& Kalivas, P. W. (1988). The effect of cholinergic stimulation in the nucleus accumbens on locomotor behavior. Brain Research, 441, 209-214.

BaKSHI, V. P., \& Kelley, A. E. (1994). Sensitization and conditioning of feeding following multiple morphine microinjections in the nucleus accumbens. Brain Research, 648, 342-346.

Bals-Kubik, R., Ableitner, A., Herz, A., \& Shippenberg, T. S. (1993). Neuroanatomical sites mediating the motivational effects of opioids as mapped by the conditioned place preference paradigm in rats. Journal of Pharmacology \& Experimental Therapeutics, 264, 489-495.

BARDO, M. T. (1998). Neuropharmacological mechanisms of drug reward: Beyond dopamine in the nucleus accumbens. Critical Reviews in Neurobiology, 12, 37-67.

BARDO, M. T., \& HAMMER, R. P., JR. (1991). Autoradiographic localization of dopamine $\mathrm{D} 1$ and $\mathrm{D} 2$ receptors in the rat nucleus accumbens: Resistance to differential rearing conditions. Neuroscience, 45, 281-290.

BenNeTt, B. D., \& Bolam, J. P. (1993). Characterization of calretininimmunoreactive structures in the striatum of the rat. Brain Research, 609, 137-148.

BennetT, B. D., \& Bolam, J. P. (1994). Synaptic input and output of parvalbumin-immunoreactive neurons in the neostriatum of the rat. Neuroscience, 62, 707-719.

Berendse, H. W., \& Groenewegen, H. J. (1990). Organization of the thalamostriatal projections in the rat, with special emphasis on the ventral striatum. Journal of Comparative Neurology, 299, 187-228.

Berridge, C. W., Stratford, T. L., Foote, S. L., \& Kelley, A. E. (1997). Distribution of dopamine $\beta$-hydroxylase-like immunoreactive fibers within the shell subregion of the nucleus accumbens. Synapse, 27, 230-241

Bouthenet, M.-L., Soutl, E., Martres, M.-P., Sokoloff, P., Giros, B., \& SCHWARTZ, J.-C. (1991). Localization of dopamine D3 receptor mRNA in the rat brain using in situ hybridization histochemistry: Comparison with dopamine D2 receptor mRNA. Brain Research, 564, 203-219.

Broek kamp, C. L. E., Pijnendurg, A. J. J., Cools, A. R., \& Van Rossum, J. M. (1975). The effect of microinjections of amphetamine into the neostriatum and the nucleus accumbens on self-stimulation behavior. Psychopharmacologia, 42, 179-183.

Brog, J. S., SalyaPongse, A., DeutCh, A. Y., \& ZahM, D. S. (1993). The patterns of afferent innervation of the core and shell in the "accumbens" part of the rat ventral striatum: Immunohistochemical detection of retrogradely transported fluoro-gold. Journal of Comparative Neurology, 338, 255-278.

Bubser, M., \& KoCH, M. (1994). Prepulse inhibition of the acoustic startle response of rats is reduced by 6-hydroxydopamine lesions of the medial prefrontal cortex. Psychopharmacology, 113, 487-492.

Burns, L. H., Arnett, L., Kelley, A. E., Everitt, B. J., \& RobBins, T. W. (1996). Effects of lesions to amygdala, ventral subiculum, medial prefrontal cortex, and nucleus accumbens on the reaction to novelty: Implication for limbic-striatal interactions. Behavioral Neuroscience, $110,60-73$.

CAINE, S. B., \& KOOB, G. F. (1993). Modulation of cocaine selfadministration in the rat through D-3 dopamine receptors. Science, 260, 1814-1816.

Callaway, C. W., Hakan, R. L., \& Henriksen, S. J. (1991). Distribution of amygdala input to the nucleus accumbens septi-An electrophysiological investigation. Journal of Neural Transmission, 83, 215-226.

Cervo, L., \& Samanin, R. (1995). Effects of dopaminergic and glutamatergic receptor antagonists on the acquisition and expression of cocaine conditioning place preference. Brain Research, 67, 242-250.

Chang, H. T., \& KitaI, S. T. (1985). Projection neurons of the nucleus accumbens: An intracellular labeling study. Brain Research, 347, 112-116.

Chang, H. T., \& Kitai, S. T. (1986). Intracellular recordings from rat nucleus accumbens neurons in vitro. Brain Research, 366, 392-396.

Chronister, R. B., Sikes, R. W., Trow, T. W., \& DeFrance, J. F. (1981). The organization of nucleus accumbens. In R. B. Chronister \& J. F. DeFrance (Eds.), The neurobiology of the nucleus accumbens (pp. 147-172). Brunswick, ME: The Haer Institute for Electrophysiological Research.

ChurChill, L., Klitenick, M. A., \& Kalivas, P. W. (1998). Dopamine depletion reorganizes projections from the nucleus accumbens and ventral pallidum that mediate opioid-induced motor activity. Journal of Neuroscience, 18, 8074-8085.

Churchill, L., Roques, B. P., \& Kalivas, P. W. (1995). Dopamine depletion augments endogenous opioid-induced locomotion in the nucleus accumbens using both $\mu$ and $\delta$ opioid receptors. Psychophar macology, 120, 347-355.

CobB, B. L., Ryan, K. L., Frei, M. R., Guelgomez, V., \& Mrckley, G. A. (1995). Chronic administration of L-NAME in drinking water alters working memory in rats. Brain Research Bulletin, 38, 203-207.

Cools, A. R., Van den Bos, R., Ploeger, G., \& Ellenbroek, B. A. (1991). Gating function of neoradrenaline in the ventral striatum: Its role in behavioural responses to environmental and pharmacological 
challenges. In P. Willner \& J. Scheel-Krüger (Eds.), The mesolimbic dopamine system: From motivation to action (pp. 141-173). Chichester, U.K.: Wiley.

De Belleroche, J. S., \& Gardiner, I. M. (1982). Cholinergic action in the nucleus accumbens: Modulation of dopamine and acetylcholine release. British Journal of Pharmacology, 75, 359-365.

Delle Donne, K. T., Sesack, S. R., \& Pickel, V. M. (1997). Ultrastructural immunocytochemical localization of the dopamine D2 receptor within GABAergic neurons of the rat striatum. Brain Research 746, 239-255.

DeUtCh, A. Y., \& CAMERon, D. S. (1992). Pharmacological characterization of dopamine systems in the nucleus accumbens core and shell. Neuroscience, 46, 49-56.

Dimova, R., Vuillet, J., Nieoullon, A., \& Kerkerian-Le GofF, L. (1993). Ultrastructural features of the choline acetyltransferasecontaining neurons and relationships with nigral dopaminergic and cortical afferent pathways in the rat striatum. Neuroscience, 53, 1059 1071 .

DoherTy, M. D., \& GratTon, A. (1996). Medial prefrontal cortical D1 receptor modulation of the meso-accumbens dopamine response to stress: An electrochemical study in freely-behaving rats. Brain $R e-$ search, 715, 86-97.

DOMESICK, V. B. (1981). Further observations on the anatomy of nucleus accumbens and caudatoputamen in the rat: Similarities and contrasts In R. B. Chronister \& J. F. DeFrance (Eds.), The neurobiology of the nucleus accumbens (pp. 7-39). Brunswick, ME: The Haer Institute for Electrophysiological Research.

Egan, M. F., Hurd, Y. L., Hyde, T. M., Weinberger, D. R., Wyatt, R. J., \& KLEINMAN, J. E. (1994). Alterations in mRNA levels of D2 receptors and neuropeptides in striatonigral and striatopallidal neurons of rats with neuroleptic-induced dyskinesias. Synapse, 18, 178-189.

EveritT, B. J., CADOR, M., \& RoBbins, T. W. (1989). Interactions between the amygdala and ventral striatum in stimulus-reward associations: Studies using a second-order schedule of sexual reinforcement. Neuroscience, 30, 63-75.

FEIFEL, D., \& SwerdLow, N. R. (1997). The modulation of sensorimotor gating deficits by mesolimbic cholecystokinin. Neuroscience Letters, 229, 5-8.

FoNNUM, F., \& WALAAS, I. (1981). Localization of neurotransmitters in nucleus accumbens. In R. B. Chronister \& J. F. DeFrance (Eds.), The neurobiology of the nucleus accumbens (pp. 259-272). Brunswick, ME: The Haer Institute for Electrophysiological Research.

Freund, T. F., Powell, J. F., \& SMiTH, A. D. (1984). Tyrosine hydroxylaseimmunoreactive boutons in synaptic contact with identified striatonigral neurons, with particular reference to dendritic spines. Neuroscience, 13, 1189-1215.

FujiYama, F., \& Masuko, S. (1996). Association of dopaminergic terminals and neurons releasing nitric oxide in the rat striatum: An electron microscopic study using NADPH-diaphorase histochemistry and tyrosine hydroxylase immunohistochemistry. Brain Research Bulletin, 40, $121-127$.

GAFFAN, I., \& HARRISON, M. (1987). Amygdalectomy and disconnection in visual learning for auditory secondary reinforcement by monkeys. Journal of Neuroscience, 7, 2285-2292.

GarTHWATte, J. (1991). Glutamate, nitric oxide and cell-cell signalling in the nervous system. Trends in Neuroscience, 14, 60-67.

Gerfen, C. R., Engber, T. M., Mahan, L. C., Susel, Z., Chase, T. N., Monsma, F. J., JR., \& SiBlEY, D. R. (1990). D1 and D2 dopamine receptor-regulated gene expression of striatonigral and striatopallidal neurons. Science, 250, 1429-1432.

Grace, A. A. (1991). Phasic versus tonic dopamine release and the modulation of dopamine system responsivity: A hypothesis for the etiology of schizophrenia. Neuroscience, 41, 1-24.

Gracy, K. N., \& PiCKel, V. M. (1996). Ultrastructural immunocytochemical localization of the $N$-methyl-D-aspartate receptor and tyrosine hydroxylase in the shell of the rat nucleus accumbens. Brain Research, 739, 169-181.

GraCY, K. N., \& PICKEL, V. M. (1997). Ultrastructural localization and comparative distribution of nitric oxide synthase and $N$-methyl-D-as- partate receptors in the shell of the rat nucleus accumbens. Brain Research, 747, 259-272.

Gracy, K. N., Svingos, A. L., \& Pickel, V. M. (1997). Dual ultrastructural localization of $\mu$-opioid receptors and NMDA-type glutamate receptors in the shell of the rat nucleus accumbens. Journal of Neuroscience, 17, 4839-4848.

Groenewegen, H. J., \& Russchen, F. T. (1984). Organization of the efferent projections of the nucleus accumbens to pallidal, hypothalamic, and mesencephalic structures: A tracing and immunohistochemical study in the cat. Journal of Comparative Neurology, 223 , 347-367.

Groenewegen, H. J., Vermeulen-Van der Zee, E., te KortSCHOT, E., \& WITTER, M. P. (1987). Organization of the projections from the subiculum to the ventral striatum in the rat: A study using anterograde transport of Phaseolus vulgaris-leucoagglutinin. Neuroscience, 23, 103-120.

Heimer, L., \& WILSON, R. D. (1975). The subcortical projections of the allocortex: Similarities in the neural association of the hippocampus, the piriform cortex, and the neocortex. In M. Santini (Ed.), Golgi Centennial Symposium: Perspectives in neurobiology (pp. 177-193). New York: Raven.

Heimer, L., Zahm, D. S., Churchill, L., Kalivas, P. W., \& WohltMANN, C. (1991). Specificity in the projection patterns of accumbal core and shell in the rat. Neuroscience, 41, 89-125.

Henselmans, J. M. L., \& Stoof, J. C. (1991). Regional differences in the regulation of acetylcholine release upon D-2 dopamine and $N$-methyl$D$-aspartate receptor activation in rat nucleus accumbens and neostriatum. Brain Research, 566, 8-12.

Herkenham, M. (1987). Mismatches between neurotransmitter and receptor localizations in brain: Observations and implications. Neuroscience, 23, 1-38.

Herkenham, M., Moon Edley, S., \& Stuart, J. (1984). Cell clusters in the nucleus accumbens of the rat, and the mosaic relationship of opiate receptors, acetylcholinesterase and subcortical afferent terminations. Neuroscience, 11, 561-593.

Hirol, N. (1995). Compartmental organization of calretinin in the rat striatum. Neuroscience Letters, 197, 223-226.

Hussain, Z., JoHnson, L. R., \& TOTTERDELl, S. (1996). A light and electron microscopic study of NADPH-diaphorase-, calretinin- and parvalbumin-containing neurons in the rat nucleus accumbens. Journal of Chemical Neuroanatomy, 10, 19-39.

Johnson, L., Aylward, R. L. M., Hussain, Z., \& Totterdell, S (1994). Input from the amygdala to the rat nucleus accumbens: Its relationship with tyrosine hydroxylase immunoreactivity and identified neurons. Neuroscience, 61, 851-865.

Johnson, L., Aylward, R. L. M., \& TotTerdell, S. (1994a). Convergence of limbic afferents and the mesolimbic dopamine system in the nuclus accumbens: Anatomical studies in the rat. Its implication for schizophrenia. In C. Haslam, J. Ewing, R. Farnbach, U. Johns, \& B. Weekes (Eds.), Cognitive functions in health, disease and disorder (Proceedings of the 17th Annual Brain Impairment Conference) (pp. 137-144). Brisbane: Australian Academic Press.

Johnson, L., Aylward, R. L. M., \& TotTerdell, S. (1994b). Synaptic organization of the amygdalar input to the nucleus accumbens in the rat. In G. Percheron, J. S. McKenzie, \& J. S. Féger (Eds.), Basal ganglia IV (pp. 109-114). New York: Plenum.

Jongen-RÊLO, A. L., Docter, G. J., JoNkER, A. J., \& VoORN, P. (1995) Differential localization of mRNAs encoding dopamine D1 or D2 receptors in cholinergic neurons in the core and shell of the rat nucleus accumbens. Molecular Brain Research, 28, 169-174.

Jongen-RÊlo, A. L., Groenewegen, H. J., \& VooRn, P. (1993). Evidence for a multi-compartmental histochemical organization of the nucleus accumbens in the rat. Journal of Comparative Neurology, 337, 267-276.

Jongen-RÊLo, A. L., Voorn, P., \& Groenewegen, H. J. (1994). Immunohistochemical characterization of the shell and core territories of the nucleus accumbens in the rat. European Journal of Neuroscience, 6, 1255-1264.

Kalivas, P. W., Churchill, L., \& Klitenick, M. A. (1993). The cir- 
cuitry mediating the translation of motivational stimuli into adaptive motor responses. In P. W. Kalivas \& C. D. Barnes (Eds.), Limbic motor circuits and neuropsychiatry (pp. 193-236). Boca Raton, FL: CRC.

Kalivas, P. W., \& DufFY, P. (1995). Selective activation of dopamine transmission in the shell of the nucleus accumbens by stress. Brain Research, 675, 325-328.

KaWAGUCHI, Y. (1993). Physiological, morphological, and histochemical characterization of three classes of interneurons in rat neostriatum. Journal of Neuroscience, 13, 4908-4923.

KAWAGUCHI, Y., \& KUBOTA, Y. (1995). Local circuit neurons in the fronta cortex and the neostriatum. In M. Kimura \& A. Graybiel (Eds.), Functions of the cortico-basal ganglia loop (pp. 73-88). Tokyo: SpringerVerlag.

KaWaguChi, Y., Wilson, C. J., Augood, S. J., \& Emson, P. C. (1995) Striatal interneurones: Chemical, physiological and morphological characterization. Trends in Neurosciences, 18, 527-535.

Kebabian, J. W., \& CalNE, D. B. (1979). Multiple receptors for dopamine. Nature, 277, 93-96.

Kelley, A. E., Smith-Roe, S. L., \& Holahan, M. R. (1997). Responsereinforcement learning is dependent on $N$-methyl-D-aspartate receptor activation in the nucleus accumbens core. Proceedings of the $\mathrm{Na}$ tional Academy of Science, 94, 12174-12179.

Kelley, A. E., \& Swanson, C. J. (1997). Feeding induced by blockade of AMPA and kainate receptors within the ventral striatum: A microinfusion mapping study. Behavioural Brain Research, 89, 107-113.

KIM, H.-S., \& PARK, W.-K. (1995). Nitric oxide mediation of cocaineinduced dopaminergic behaviors: Ambulation-accelerating activity, reverse tolerance and conditioned place preference in mice. Journal of Pharmacology \& Experimental Therapeutics, 275, 551-557.

KIM, J. S., \& LEVINE, E. D. (1996). Nicotinic, muscarinic and dopaminergic actions in the ventral hippocampus and the nucleus accumbens: Effects on spatial working memory in rats. Brain Research, 725, 231-240.

Kivastik, T., Rutkauskaite, J., \& Zharkovsky, A. (1996). Nitric oxide synthesis inhibition attenuates morphine-induced place pref erence. Pharmacology, Biochemistry, \& Behavior, 53, 1013-1015.

KLARNER, A., KOCH, M., \& SCHNitzler, H. U. (1997). Induction of Fos-protein in the forebrain and disruption of sensorimotor gating following $N$-methyl-D-aspartate infusion into the ventral hippocampus of the rat. Neuroscience, 84, 443-452.

KODSI, M. H., \& SWERDLOW, N. R. (1997). Reduced prepulse inhibition after electrolytic lesions of nucleus accumbens subregions in the rat. Brain Research, 773, 45-52.

Kretschmer, B. D., \& КосH, M. (1997). Role of the strychnineinsensitive glycine binding site in the nucleus accumbens and anterodorsal striatum in sensorimotor gating: A behavioral and microdialysis study. Psychopharmacology, 130, 131-138.

Lacroix, L., Broersen, L. M., Weiner, I., \& Feldon, J. (1998). The effects of excitotoxic lesion of the medial prefrontal cortex on latent inhibition, prepulse inhibition, food hoarding, elevated plus maze, active avoidance and locomotor activity in the rat. Neuroscience, $\mathbf{8 2}$, $431-442$

LanNes, B., \& Micheletti, G. (1994). Glutamate-dopamine balance in the striatum: Pre- and post-synaptic interactions. In G. Percheron, J. S McKenzie, \& J. S. Féger (Eds.), Basal ganglia IV (pp. 475-489). New York: Plenum

Lehman, J., \& LANGER, S. Z. (1983). The striatal cholinergic interneuron: Synaptic target of dopaminergic terminals? Neuroscience, $10,1105-1120$.

Le Moine, C., \& Bloch, B. (1996). Expression of the D3 dopamine receptor in peptidergic neurons of the nucleus accumbens: Comparison with the D1 and D2 dopamine receptors. Neuroscience, 73, 131-143.

Lévesque, D., Martres, M.-P., Diaz, J., Griffon, N., Lammers, C. H., SOKOLOFF, P., \& SCHWARTZ, J.-C. (1995). A paradoxical regulation of the dopamine D3 receptor expression suggests the involvement of an anterograde factor from dopamine neurons. Proceedings of the National Academy of Science, 92, 1719-1723.

LI, Y. Q., RAo, Z. R., \& SHI, J. W. (1989). Serotoninergic projections from the midbrain periaqueductal gray to the nucleus accumbens in the rat. Neuroscience Letters, 98, 276-279.
MA, J., BRUdZYNSKI, S. M., \& LEUNG, L.-W. S. (1996). Involvement of the nucleus accumbens-ventral pallidal pathway in postictal behavior induced by a hippocampal afterdischarge in rats. Brain Research, 739, 26-35.

Maldonado-IrizarRy, C. S., \& Kelley, A. E. (1995). Excitatory amino acid receptors within nucleus accumbens subregions differentially mediate spatial learning in the rat. Behavioral Pharmacology, 6, 527-539.

MalenKa, R. C., \& Nicoll, R. A. (1993). NMDA-receptor-dependent synaptic plasticity: Multiple forms and mechanisms. Trends in Neurosciences, 16, 521-526.

Maragos, W. F., Penney, J. B., \& YounG, A. B. (1988). Anatomic correlation and $3 \mathrm{H}-\mathrm{TCP}$-labeled receptors in rat brain. Journal of Neuroscience, $8,493-501$.

MATthYSSE, S. (1978). A theory of the relation between dopamine and attention. In L. C. Wynne, R. L. Cromwell, \& S. Matthysse (Eds.), The nature of schizophrenia (pp. 307-310). New York: Wiley.

Meredith, G. E., Agolia, R., Arts, M. P. M., Groenewegen, H. J., \& ZAHM, D. S. (1992). Morphological differences between projection neurons of the core and shell in the nucleus accumbens of the rat. Neuroscience, 50, 149-162.

Meredith, G. E., Blank, B., \& Groenewegen, H. J. (1989). The distribution and compartmental organization of the cholinergic neurons in nucleus accumbens of the rat. Neuroscience, 31, 327-345.

MERedith, G. E., \& Chang, H. T. (1994). Synaptic relationships of enkephalinergic and cholinergic neurons in the nucleus accumbens of the rat. Brain Research, 667, 67-76.

Meredith, G. [E.], Egan, M. F., Tipper, G., Wong, M. L., \& Hyde, T. (1997). Ultrastructural changes in dynorphinergic terminals of nucleus accumbens in rats that display neuroleptic-induced vacuous chewing movements. Society for Neuroscience Abstracts, 23, 399.

Meredith, G. E., Ingham, C. A., Voorn, P., \& Arbuthnott, G. W. (1993). Ultrastructural characteristics of enkephalin-immunoreactive boutons and their postsynaptic targets in the shell and core of the nucleus accumbens of the rat. Journal of Comparative Neurology, 332 , 224-236.

Meredith, G. E., Pattiselanno, A., Groenewegen, H. J., \& Haber, S. N. (1996). The shell and core in monkey and human nucleus accumbens identified with antibodies to calbindin- $\mathrm{D}_{28 \mathrm{k}}$. Journal of Comparative Neurology, 365, 628-639.

Meredith, G. E., Pennartz, C., \& Groenewegen, H. J. (1993). The cellular framework for chemical signalling in the nucleus accumbens. In G. W. Arbuthnott \& P. C. Emson (Eds.), Basal ganglia: Progress in Brain Research (Vol. 99, pp. 3-24). Amsterdam: Elsevier.

Meredith, G. E., \& TiPPER, G. (1996). [Dynorphin-immunoreactive terminals and their postsynaptic targets in the shell of nucleus accumbens]. Unpublished raw data.

MEREDITH G. E., \& WouterLOOD, F. G. (1990). Hippocampal and midline thalamic fibers and terminals in relation to the choline acetyltransferase-immunoreactive neurons in nucleus accumbens of the rat: A light and electron microscopic study. Journal of Comparative Neurology, 296, 204-221.

Meredith, G. E., Wouterlood, F. G., \& Pattiselanno, A. (1990) Hippocampal fibers make synaptic contacts with glutamate decarboxylase-immunoreactive neurons in the rat nucleus accumbens. Brain Research, 513, 329-334.

Meredith, G. E., YPMA, P., \& ZAHM, D. S. (1995). The effects of dopamine depletion on the morphology of medium spiny neurons in the shell and core of the rat nucleus accumbens. Journal of Neuroscience, 15, 3808-3820.

Michaels, R. L., \& Rothman, S. M. (1990). Glutamate neurotoxicity in vitro: Antagonist pharmacology and intracellular calcium concentrations. Journal of Neuroscience, 10, 283-292.

Mogenson, G. J., Brudzynski, S. M., Wu, M., Yang, C. R., \& Yim C. Y. (1993). From motivation to action: A review of dopaminergic regulation of limbic-nucleus accumbens-ventral pallidum-pedunculopontine nucleus circuitries involved in limbic-motor integration. In P. W. Kalivas \& C. D. Barnes (Eds.), Limbic motor circuits and neuropsychiatry (pp. 193-236). Boca Raton, FL: CRC. 
Mogenson, G. J., Jones, D. L., \& YIM, C. Y. (1980). From motivation to action: Functional interface between the limbic system and the motor system. Progress in Neurobiology, 14, 69-97.

Mogenson, G. J., \& YIM, C. Y. (1981). Electrophysiological and neuropharmacological-behavioral studies of the nucleus accumbens: Implications for its role as a limbic-motor interface. In R. B. Chronister \& J. F. DeFrance (Eds.), The neurobiology of the nucleus accumbens (pp. 210-229). Brunswick, ME: The Haer Institute for Electrophysiological Research.

Nauta, W. J. H., Smith, G. P., FAull, R. L., \& Domesick, V. B. (1978). Efferent connections and nigral afferents of the nucleus accumbens septi in the rat. Neuroscience, 3, 385-401.

O'DonNELL, P. (1999). Ensemble coding in the nucleus accumbens. Psychobiology, 27, 000-000.

O'Donnell, P., \& Grace, A. A. (1993a). Dopaminergic modulation of dye coupling between neurons in the core and shell regions of the nucleus accumbens. Journal of Neuroscience, 13, 3456-3471.

O'Donnell, P., \& Grace, A. A. (1993b). Physiological and morphological properties of accumbens core and shell neurons recorded in vitro. Synapse, 13, 135-160.

O'DONNELL, P., \& GRACE, A. A. (1995). Synaptic interactions among excitatory afferents to nucleus accumbens neurons: Hippocampal gating of prefrontal cortical input. Journal of Neuroscience, 15, 3622-3639.

Pennartz, C. M. A., Ameerun, R. F., Groenewegen, H. J., \& Lopes DA Silva, F. H. (1993). Synaptic plasticity in an in vitro slice preparation of the rat nucleus accumbens. European Journal of Neuroscience, 5, 107-117.

Pennartz, C. M. A., Boeijinga, P. H., \& Lopes da Silva, F. H. (1990). Locally evoked potentials in slices of the rat nucleus accumbens: NMDA and non-NMDA receptor mediated components and modulation by GABA. Brain Research, 529, 30-41.

Pennartz, C. M. A., Dolleman-Van der Weel, M. J., Kitai, S. T., \& LOPES DA SILVA, F. H. (1992). Presynaptic dopamine D1 receptors attenuate excitatory and inhibitory limbic inputs to the shell region of the rat nucleus accumbens studied in vitro. Journal of Neurophysiology, 67, 1325-1334.

Pennartz, C. M. A., Dolleman-Van der Weel, M. J., \& Lopes DA Silva, F. H. (1992). Differential membrane properties and dopamine effects in the shell and core of the rat nucleus accumbens studied in vitro. Neuroscience Letters, 136, 109-112.

Pennartz, C. M. A., Groenewegen, H. J., \& Lopes da Silva, F. H. (1994). The nucleus accumbens as a complex of functionally distinct neuronal ensembles; an integration of behavioural, electrophysiological and anatomical data. Progress in Neurobiology, 42, 719-761.

Pennartz, C. M. A., \& Kitai, S. T. (1991). Hippocampal inputs to identified neurons in an in vitro slice preparation of the rat nucleus accumbens: Evidence for feed-forward inhibition. Journal of Neuroscience, 11, 2838-2847.

Pennartz, C. M. A., \& Lopes da Silva, F. H. (1994). Muscarinic modulation of synaptic transmission in rat nucleus accumbens slices is frequency-dependent. Brain Research, 645, 231-239.

PhelPS, P. E., \& VAUGHN, J. E. (1986). Immunocytochemical localization of choline acetyltransferase in rat ventral striatum: A light and electron microscopic study. Journal of Neurocytology, 15, 595-617.

Pickel, V. M., Joh, T. H., \& CHan, J. (1988). Substance P in the rat nucleus accumbens: Ultrastructural localization in axon terminals and their relation to dopaminergic afferents. Brain Research, 444, 247-264.

Pierce, R. C., Bell, K., Duffy, P., \& Kalivas, P. W. (1996). Repeated cocaine augments excitatory amino acid transmission in the nucleus accumbens only in rats having developed behavioral sensitization. Journal of Neuroscience, 16, 1550-1560.

Pierce, R. C., \& Kalivas, P. W. (1995). Amphetamine produces sensitized increases in locomotion and extracellular dopamine preferentially in the nucleus accumbens shell of rats administered repeated cocaine. Journal of Pharmacology \& Experimental Therapeutics, 275, 1019-1029.

Pijnendurg, A. J. J., Honig, W. M. M., \& Van Rossum, J. M. (1975). Antagonism of apomorphine and d-amphetamine-induced stereotyped behaviour by injection of low doses of haloperidol into the caudate nucleus and nucleus accumbens. Psychopharmacologia, 45, 65-71.
Pijnenburg, A. J. J., \& Van Rossum, J. M. (1973). Stimulation of locomotor activity following injection of dopamine into the nucleus accumbens. Journal of Pharmacological Pharmacology, 25, 1003-1005.

Prinssen, E. P. M., Balestra, W., Bemelmans, F. F. J., \& Cools, A. R. (1994). Evidence for a role of the shell of the nucleus accumbens in oral behavior of freely moving rats. Joumal of Neuroscience, 14, 1555-1562.

Pulvirenti, L., Balducci, C., \& KoOB, G. F. (1996). Inhibition of nitric oxide synthesis reduces intravenous cocaine self-administration in the rat. Neuropharmacology, 35, 1811-1814.

RaWLs, S. M., \& McGinTY, J. F. (1998). Kappa receptor activation attenuates L-trans-pyrrolidine-2,4-dicarboxylic acid-evoked glutamate levels in the striatum. Journal of Neurochemistry, 70, 626-634.

Rebec, G. V., Grabner, C. P., Johnson, M., Pierce, R., \& Bardo, M. T. (1997). Transient increases in catecholaminergic activity in medial prefrontal cortex and nucleus accumbens shell during novelty. Neuroscience, 76, 707-714.

RobBins, T. W., \& EveriTT, B. J. (1992). Functions of dopamine in the dorsal and ventral striatum. Seminars in the Neurosciences, 4, 119-127.

RoBINSON, T. E., \& KolB, B. (1997). Persistent structural modifications in nucleus accumbens and prefrontal cortex neurons produced by previous experience with amphetamine. Journal of Neuroscience, 17 , 8491-8497.

SADIKOT, A. F., Rudkin, T. M., \& SMITH, Y. (1996). The amygdalostriatal projection: An analysis of synaptic inputs to GABAergic interneuron subtypes. In Y. Ohye, H. Narabayashi, M. Segawa, K. Nakano, T. Shibasaki, M. Hirato, \& M. Matsumura (Eds.), The basal ganglia V (pp. 33-42). New York: Plenum.

Salamone, J. D., Cousins, M. S., \& Bucher, S. (1994). Anhedonia or anergia? Effects of haloperidol and nucleus accumbens dopamine depletion on instrumental response selection in a T-maze cost/benefit procedure. Behavioural Brain Research, 65, 221-229.

Salamone, J. D., Kurth, P., McCullough, L. D., Sokolowski, J. D., \& Cousins, M. S. (1993). The role of brain dopamine in response initiation: Effects of haloperidol and regionally specific dopamine depletions on the local rate of instrumental responding. Brain $R e$ search, 628, 218-226.

Schacter, G. B., YANG, C. R., InNis, N. K., \& Mogenson, G. J. (1989). The role of the hippocampal-nucleus accumbens pathway in radialarm maze performance. Brain Research, 494, 339-349.

Schmauss, C., Haroutunian, V., Davis, K. L., \& Davidson, M. (1993) Selective loss of dopamine D3-type receptor mRNA expression in parietal and motor cortices of patients with chronic schizophrenia. Proceedings of the National Academy of Science, 90, 8942-8946.

SeE, R. E., \& Chapman, M. A. (1994). Chronic haloperidol, but not clozapine, produces altered oral movements and increased extracellular glutamate in rats. European Journal of Pharmacology, 263, 269-276.

SEGAL, M. (1995). Dendritic spines for neuroprotection: A hypothesis Trends in Neurosciences, 18, 468-471.

SESACK, S. R., \& PICKeL, V. M. (1990). In the rat medial nucleus accumbens, hippocampal and catecholaminergic terminals converge on spiny neurons and are in apposition to each other. Brain Research, 527, 266-279.

Sesack, S. R., \& Pickel, V. M. (1992). Prefrontal cortical efferents in the rat synapse on unlabeled neuronal targets of catecholamine terminals in the nucleus accumbens septi and on dopamine neurons in the ventral tegmental area. Journal of Comparative Neurology, $\mathbf{3 2 0}$, $145-160$.

Sorg, B. A., Guminski, B. J. M., Hooks, M. S., \& Kalivas, P. W. (1995). Cocaine alters glutamic acid decarboxylase differentially in the nucleus accumbens core and shell. Molecular Brain Research, 29, 381-386.

SPIEGLER, B. J., \& MishKin, M. (1981). Evidence for the sequential participation of inferior temporal cortex and amygdala in the acquisition of stimulus-reward associations. Behavioral Brain Research, 3, 303-317.

STEVENS, J. (1973). An anatomy of schizophrenia? Archives of General Psychiatry, 29, 177-189.

SudHa, S., \& Pradhan, N. (1995). Stress-induced changes in regional monoamine metabolism and behavior in rats. Physiology \& Behaviour, 57, 1061-1066.

Sugita, S., UChimura, N., JiANG, Z.-G., \& NorTh, R. A. (1991). Dis- 
tinct muscarinic receptors inhibit release of $\gamma$-aminobutyric acid and excitatory amino acids in mammalian brain. Proceedings of the $\mathrm{Na}$ tional Academy of Sciences, 88, 2608-2611.

Svingos, A. L., Clarke, C. L., \& Pickel, V. M. (1998). Cellular sites for activation of delta-opioid receptors in the rat nucleus accumbens shell: Relationship with Met ${ }^{5}$-enkephalin. Journal of Neuroscience, 18, 1923-1933.

Svingos, A. L., Moriwaki, A., Wang, J. B., Uhl, G. R., \& Pickel, V. M. (1996). Ultrastructural immunocytochemical localization of $\mu$ opioid receptors in rat nucleus accumbens: Extrasynaptic plasmalemmal distribution and association with Leu ${ }^{5}$-enkephalin. Journal of Neuroscience, 16, 4162-4173.

Tagaki, H., Mizuta, H., Matsuda, T., Inagaki, S. M., Tateishi, K., \& HАMOKA, T. (1984). The occurrence of cholecystokinin-like immunoreactive neurons in the rat neostriatum: Light and electron microscopic analysis. Brain Research, 309, 346-349.

Theriault, E., \& LANDIS, D. M. D. (1987). Morphology of striatal neurons containing VIP-like immunoreactivity. Journal of Comparative Neurology, 268, 29-37.

Thomas, E. J., Vaid, R. R., \& TotTerdell, S. (1995). An estimate of the proportion of interneurons in the nucleus accumbens. Brain Research Association Abstracts, 12, 40 .

TotTerdell, S., \& Hussain, Z. (1996). [An electron microscopic study of parvalbumin and calretinin interneurons in nucleus accumbens] Unpublished raw data.

TotTERDELl, S., \& McFarLANE, A. (1998). [An electron microscopic study of the ventral tegmental area projections to interneurons containing nitric oxide synthase in nucleus accumbens]. Unpublished raw data.

Totterdell, S., \& Meredith, G. E. (1997). Topographical organization of projections from the entorhinal cortex to the striatum of the rat. Neuroscience, 78, 715-729.

TotTerdell, S., \& Smith, A. D. (1989). Convergence of hippocampal and dopaminergic input onto identified neurons in the nucleus accumbens of the rat. Journal of Chemical Neuroanatomy, 2, 285-298.

Van Bockstaele, E. J., \& Pickel, V. M. (1993). Ultrastructure of serotonin-immunoreactive terminals in the core and shell of the rat nucleus accumbens - Cellular substrates for interactions with catecholamine afferents. Journal of Comparative Neurology, 334, 603617.

VAn Bockstaele, E. J., Sesack, S. R., \& Pickel, V. M. (1994). Dynorphinimmunoreactive terminals in the rat nucleus accumbens: Cellular sites for modulation of target neurons and interactions with catecholamine afferents. Journal of Comparative Neurology, 341, 1-15.

VERTES, R. P. (1991). A PHA-L analysis of ascending projections of the dorsal raphe nucleus in the rat. Journal of Comparative Neurology, 313, 643-668.

VOORN, P., Docter, G. J., Jongen-RÊLo, A., \& Jonker, A. J. (1994) Rostrocaudal subregional differences in the response of enkephalin, dynorphin and substance $P$ synthesis in rat nucleus accumbens to dopamine depletion. European Journal of Neuroscience, 6, 486-496.

VoORN, P., Gerfen, C. R., \& Groenewegen, H. J. (1989). The compartmental organization of the ventral striatum of the rat: Immunohistochemical distribution of enkephalin, substance P, dopamine, and calcium binding protein. Journal of Comparative Neurology, 289, 189-201.

Voorn, P., Jorritsma-Byham, B., VAN DiJk, C., \& Buiss, R. M. (1986). The dopaminergic innervation of the ventral striatum in the rat: $A$ light- and electron-microscopical study with antibodies against dopamine. Journal of Comparative Neurology, 251, 84-99.

Vuillet, J., Kerkerian, L., Kachidian, P., Bosler, O., \& NieoulLON, A. (1989). Ultrastructural correlates of functional relationships between nigal dopaminergic or cortical afferent fibres and neuropeptide Y-containing neurons in the rat striatum. Neuroscience Letters, 100, 99-104.

Wan, F. J., Caine, S. B., \& Swerdlow, N. R. (1996). The ventral subiculum modulation of prepulse inhibition is not mediated via dopamine D2 or nucleus accumbens non-NMDA glutamate receptor activity. European Journal of Pharmacology, 314, 9-18.

WAN, F. J., \& SWERDLOW, N. R. (1996). Sensorimotor gating in rats is regulated by different dopamine-glutamate interaction in the nucleus accumbens core and shell regions. Brain Research, 722, 168-176.

WEINER, I. (1990). Neural substrates of latent inhibition: The switching model. Psychological Bulletin, 108, 442-461

Wilkinson, L. S., Killcross, S. S., Humby, T., Hall, F. S., Geyer, M. A., \& RobBins, T. W. (1994). Social isolation in rats produces developmentally specific deficits in prepulse inhibition of the acoustic startle response without disrupting latent inhibition. Neuropsychopharmacology, 10, 61-72.

Wilson, C. J., Groves, P. M., Kital, S. T., \& Linder, J. C. (1983). Three-dimensional structure of dendritic spines in the rat neostriatum. Journal of Neuroscience, 3, 383-398.

Wolf, M. E., Dahlin, S. L., Hu, X. T., Xue, C. J., \& White, K. (1995) Effects of lesions of prefrontal cortex, amygdala, or fornix on behavioral sensitization to amphetamine: Comparison with $N$-methyl-Daspartate antagonists. Neuroscience, 69, 417-439.

Wright, C. I., BeiJer, A. V. J., \& GroeneweGen, H. J. (1996). Basal amygdaloid complex afferents to the rat nucleus accumbens are compartmentally organized. Journal of Neuroscience, 16, 1877-1893.

Wright, C. I., \& GRoENeWEgen, H. J. (1995). Patterns of convergence and segregation in the medial nucleus accumbens of the rat: Relationships of prefrontal cortical, midline thalamic and basal amygdaloid afferents. Journal of Comparative Neurology, 361, 383-403.

YANG, C. R., \& MOGENSON, G. J. (1984). Electrophysiological responses of neurons in the nucleus accumbens to hippocampal stimulation and the attenuation of the excitatory responses by the mesolimbic dopaminergic system. Brain Research, 324, 69-84.

YIM, C. Y., \& MOGENSON, G. J. (1986). Mesolimbic dopamine projection modulates amygdala-evoked EPSP in nucleus accumbens neurons: An in vivo study. Brain Research, 369, 347-352.

Záborszky, L., Alheid, G. F., Beinfeld, M. C., Eiden, L. E., HeIMER, L., \& PAlkovits, M. (1985). Cholecystokinin innervation of the ventral striatum: A morphological and radioimmunological study. Neuroscience, 14, 427-453.

ZAнM, D. S. (1992). An electron microscopic morphometric comparison of tyrosine hydroxylase-immunoreactive innervation in the neostriatum and nucleus accumbens core and shell. Brain Research, $\mathbf{5 7 5}$, $751-756$.

ZAHM, D. S., \& BroG, J. S. (1992). On the significance of subterritories in the "accumbens" part of the rat ventral striatum. Neuroscience, $\mathbf{5 0}$ $751-767$.

ZAHM, D. S., \& HEIMER, L. (1988). Ventral striatopallidal parts of the basal ganglia in the rat: I. Neurochemical compartmentation as reflected by the distributions of neurotensin and substance $P$ immunoreactivity. Journal of Comparative Neurology, 272, 516-535.

ZAHM, D. S., \& HEIMER, L. (1993). Specificity in the efferent projections of the rat nucleus accumbens in the rat: Comparison of the rostral pole projection patterns with those of the core and shell. Journal of Comparative Neurology, 327, 220-232.

\section{APPENDIX \\ Hypothetical, Simplified Synaptic Frameworks Subserving Motivationally Related Behaviors}

\section{Novelty}

Both hippocampal and amygdalar inputs to the septal pole region of nucleus accumbens (NAc) may mediate responses to novelty. Their influences are dissociable since lesions of these regions produce qualitatively similar effects on food neophobia but opposite effects on locomotor activity. Hippocampal and amygdalar fibers form excitatory synapses with the spines of medium spiny neurons (MSNs), although not necessarily the same neurons. Dopaminergic input onto dendritic shafts, proximal to the cortical terminals, may modulate this excitatory input. Local circuit neurons (LCNs), unlikely to be PV-containing since such neurons are relatively rare in the septal pole, probably also receive amygdalar and/or hippocampal and dopaminergic in nervation. Hippocampal afferents to the NAc are probably im- 
portant in switching between behaviors, and those from the amygdala carry information about the animal's emotional state. Convergence of these two inputs would allow individual NAc neurons to integrate their signals. Segregation of inputs to separate populations of MSNs is more consistent with the observed dissociation of behaviors, although MSNs are probably interconnected via their own local axonal connections and via the inputs from LCNs.

\section{Behavioral Sensitization}

Behavioral sensitization is reportedly mediated by excitatory inputs to the septal pole region of NAc shell. Since exposure to stress produces cross-sensitization with cocaine, inputs from the prefrontal cortex (PFC) are probably of greatest relevance. In the shell, NMDA receptors are presynaptic on dopaminergic terminals, providing a specific site for the modulation of dopamine release by $\mathrm{PFC}$ afferents. The $\mathrm{PFC}$ also regulates the burst-firing pattern of the neurons that give rise to dopamine innervation of NAc. Excitatory inputs from the PFC to NAc synapse onto spines and may also innervate PV-containing or somatostatin/ NOS/ NPY-containing LCNs. These LCNs then contact projection neurons, presumably including those that receive direct prefrontal input. Outputs from the septal pole preferentially feed into limbic-related regions. Behavioral sensitization involves increased responsivity to dopamine (via D1 receptors) in NAc, perhaps related to a reported increase in spine density. Such an increase might provide more sites for (presynaptic) interactions between dopamine and cortical afferents and, hence, enhanced dopamine release in response to subsequent exposure to rewarding drugs. Since NOS inhibition significantly inhibits both cocaine- and morphine-induced conditioned place preference, this population of LCNs may be crucial in the development of increased sensitivity to dopamine.

\section{Sensorimotor Gating}

Prepulse inhibition of acoustic startle (PPI), a measure of sensorimotor gating, is regulated in both core and shell regions via complex interactions between the dopaminergic and glutamatergic inputs. Apomorphine-induced disruption of PPI is potentiated by cholecystokinin, either coreleased with dopamine or from LCNs. PPI is disrupted by large lesions of PFC and following subconvulsive doses of NMDA injected into the hippocampus. Glutamate agonist-induced disruptions of PPI are dopamine independent in the shell but are dopamine (D2) dependent in the core. It is possible that core and shell elements of PPI are related to inputs from the PFC and hippocampus, respectively. Fibers from both regions contact spines and dendrites of projection neurons and converge with dopamine input. However, in the shell, excitatory inputs are more often onto dendritic shafts: Spines as specific sites for modulation by dopamine are reduced. Dopaminergic fibers in the shell (but not core) bear presynaptic NMDA receptors that may explain why glutamate-induced PPI disruptions in the shell are dopamine independent. Stimulation ofglutamatergic afferents to NAc produces excitation followed by inhibition. Inhibition of neurons in the shell that might project to the ventral segmental area may increase dopaminergic input to both core and shell. In the shell, this elevation might be sufficient to counteract the effects of a dopamine antagonist.

(Manuscript received August 6, 1998; revision accepted for publication November 13, 1998.) 